\title{
Social Security and the Retirement and Savings Behavior of Low Income Households 1
}

\author{
Wilbert van der Klaauw and \\ Federal Reserve Bank of New York
}

Kenneth I. Wolpin

University of Pennsylvania

\begin{abstract}
In this paper, we develop and estimate a model of retirement and savings incorporating limited borrowing, stochastic wage offers, health status and survival, social security benefits, Medicare and employer provided health insurance coverage, and intentional bequests. The model is estimated on sample of relatively poor households from the first three waves of the Health and Retirement Study (HRS), for whom we would expect social security income to be of particular importance. The estimated model is used to simulate the responses to changes in social security rules, including changes in benefit levels, in the payroll tax, in the social security earnings tax and in early and normal retirement ages. Welfare and budget consequences are estimated.
\end{abstract}

\author{
Keywords \\ Retirement; Social Security; Structural Estimation
}

\section{Introduction}

The literature on retirement behavior has grown rapidly during the last twenty years. Much of that growth has been due to recent methodological advances in the structural estimation of dynamic discrete choice models of behavior under uncertainty. Unlike earlier static lifetime models (e.g., Fields and Mitchell, 1984), dynamic models account for the sequential nature of the retirement process in which individuals adjust their behavior as events unfold. Structural estimation of the fundamental parameters of preferences and constraints as opposed to "reduced form" analyses permits the simulation of policy experiments that act directly on constraints and which may be outside of current or prior policy regimes.

Much of the focus in the initial attempts to formulate and estimate a forward looking model of retirement behavior has been on explaining the empirical regularities of a declining fulltime employment rate with age (for males), with particularly large drops at ages 62 and 65 ,

\footnotetext{
${ }^{1}$ Recent Studies of the effects of similar changes in social security rules have been inconclusive. For example, French (2005) predicts no effect of raising the early retirement age on simulated work choices at age 62, but Gustman and Steinmeier (2005) forecasts a large increase in full-time employment at that age.

(C) 2008 Elsevier B.V. All rights reserved.

Corresponding Author: Wilbert van der Klaauw. Microeconomic and Regional Studies Function, Federal Reserve Bank of New York, 33 Liberty Street, New York, NY 10045. Wilbert.VanderKlaauw@ny.frb.org Tel. No. 212-720-5916, Fax: 212-720-1844.

This is a PDF file of an unedited manuscript that has been accepted for publication. As a service to our customers we are providing this early version of the manuscript. The manuscript will undergo copyediting, typesetting, and review of the resulting proof before it is published in its final citable form. Please note that during the production process errors may be discovered which could affect the content, and all legal disclaimers that apply to the journal pertain.
} 
as well as the substantial heterogeneity in retirement behavior across individuals (see Gustman and Steinmeier (1986), Stock and Wise (1990), Berkovec and Stern (1991), Phelan and Rust (1991), Lumsdaine, Stock and Wise (1992,1994,1996), Rust and Phelan (1997), Blau and Gilleskie $(2003,2005)$ ). Besides establishing the importance of health, wealth and labor market opportunities in explaining retirement patterns, these studies also point to the significance of capital and health insurance market imperfections and social security and private pension rules.

Social security rules may affect work decisions through the structure of the benefits schedule, the earnings tax and its actuarially unfair delayed retirement credit associated with postponing retirement beyond the normal retirement age. Private pensions often include substantial incentives to remain with a firm until a given age, combined with substantial incentives to leave the firm at an older age. Therefore, even in an economy with perfect capital markets where individuals can smooth consumption by borrowing against future pension and social security income, public and private pensions can produce delays in retirement and spikes in retirement rates at certain ages. However, their importance for labor supply decisions is likely to be substantially greater in the presence of borrowing constraints, which may prevent many low-wage individuals, who optimally accumulate relatively little tangible wealth, from retiring before reaching the age at which they first become eligible to receive benefits. A similar role can be attributed to the Medicare program when health insurance markets are imperfect. Limited private health insurance options could make it too risky for individuals who don't have access to employer provided retiree health insurance to retire prior to being eligible for Medicare at 65.

Rust and Phelan (1997) provides empirical evidence of the importance of market imperfections, attributing a large part of the drop in employment at age 62 to social security eligibility and at age 65 to Medicare eligibility. Blau and Gilleskie (2003,2005) also find significant, although more modest, employment effects of employer provided health insurance. However, there is an important reason to believe that the roles attributed to social security and employer provided health insurance in these studies may be overestimated. The models on which these results are based do not allow households to save, thereby removing an important instrument through which to smooth consumption (and facilitate early retirement) and to self-insure against future health expenditures. Gustman and Steinmeier $(1986,1994)$ instead make the alternative extreme assumption of perfect capital markets, in which individuals can freely borrow against future earnings and pension income, an assumption that is likely to lead to an underestimation of the importance of social security and employer linked health insurance.

Other empirical studies have found the effect of assets other than social security and pension annuities on the timing of retirement to be weak (Blau (1994), Diamond and Hausman (1984), Sickles and Taubman (1986)). However, these studies do not capture completely the complex interactions that exist between savings, health status, social security benefits, health insurance coverage and work decisions. Moreover, many of these studies take accumulated savings or assets to be exogenous in their analysis. Several studies, such as those by Feldstein (1974) and Bernheim and Levin (1989) have found social security to depress savings, which suggests that the exogeneity assumption may be incorrect.

An accurate assessment of the magnitude and manner in which social security benefits influence behavior is crucial for credibly forecasting the impact of changing the social security program, a major goal of this paper. We, therefore, develop and estimate a model of retirement and savings incorporating limited borrowing, stochastic wage offers, health status and survival, social security benefits, Medicare and employer provided health insurance coverage, and intentional bequests. The model is estimated on sample of relatively poor 
households from the first three waves of the Health and Retirement Study (HRS), for whom we would expect social security income to be of particular importance. The estimated model is used to simulate the responses to several counterfactual experiments corresponding to changes in social security rules. These include changes in benefit levels, in the payroll tax, in the social security earnings tax and in early and normal retirement ages. ${ }^{1}$

Our model shares features with many recent papers that have estimated models of retirement behavior, but is more comprehensive and introduces a number of new elements. It incorporates savings behavior with limited borrowing as in Gustman and Steinmeier (2005), French (2005) and French and Jones (2004)), and also models the joint labor supply decision of married couples as in Gustman and Steinmeier (2000) and Blau and Gilleskie (2005). The flexibility to augment household income through spousal work is potentially an important instrument to insure against wage and health shocks, as well as a tool for smoothing consumption. We explicitly incorporate the social security benefit rules which apply to couples, allow for health insurance coverage through the spouse and incorporate the possibility of direct preferences for shared leisure and of assortative mating on preferences and on health and market skill endowments.

Wages in our model are stochastic as in French (2005), but also depend on accumulated work experience and tenure and we allow individuals to change jobs which may or may not offer health insurance. Like Berkovec and Stern (1991), in characterizing employment choices we distinguish between part-time and full-time work, model job-to-job transitions and instead of treating retirement as an absorbing state, allow returns from non-employment into the labor force. However, we do not explicitly consider the purchase of private health insurance and medical expenditure decisions (Blau and Gilleskie, 2003), private pensions on current jobs (Lumsdaine, Stock and Wise 1992,1994,1996, French 2005, Blau and Gilleskie, 2003) nor do we model disability insurance applications and benefit receipt (Rust et al, 2003).

Our model accommodates observed and unobserved heterogeneity in preferences, wages, health transitions and mortality risks. In addition, individuals in our model have expectations over changes in social security policy. Myopic beliefs about the social security system may be unrealistic given the long history of changes in the social security rules and benefit levels which have been enacted over the 1969-90 period, with major changes in 1972, 1977 and 1983. As Moffitt (1987) has argued, the magnitude of behavioral responses to policy changes will depend strongly on the extent to which these policy changes were anticipated. In an analysis of data from the Survey of Economic Expectations on subjective expectations of future social benefit receipt, Dominitz, Manski and Heinz (2003) in fact conclude that a sizeable proportion of their sample, and especially among the young, consider it fairly likely that the social security program will no longer exist at the time they retire.

A final contribution of this paper is that we make explicit use of subjective expectations in the estimation of our model. The Health and Retirement Study contains a set of probabilistic questions, on, among others, retirement and longevity expectations. For example, all those employed in 1992 were asked for their subjective probability that they would be working full-time after reaching ages 62 and 65, and all respondents were asked about their probabilities of surviving to age 75 and 85 . Reported expectations about future choices have precise interpretations within the context of dynamic behavioral models. Just as current choices are taken to portray optimal behavior given current information, expectations about

\footnotetext{
${ }^{1}$ Recent Studies of the effects of similar changes in social security rules have been inconclusive. For example, French (2005) predicts no effect of raising the early retirement age on simulated work choices at age 62, but Gustman and Steinmeier (2005) forecasts a large increase in full-time employment at that age.
} 
future choices portray optimal future behavior conditional on current information. As a result, subjective data provide useful information about the decision process in the same way as do objective data (van der Klaauw (2000), Wolpin (1999)).

We highlight a few of the results of the counterfactual policy changes. ${ }^{2}$ For example, for married couples, we find that a 50 percent reduction in social security benefits would lead to a small decline in the labor supply of both spouses at ages between 51 and 61, and a substantial increase at ages between 62 and 69, an increase that is particularly large for husbands whose full-time employment rate in this latter age range is predicted by the model to increase from 37.8 to 52.3 percent. Although average annual earnings thus increase in the latter age range and average net assets optimally fall, average annual household consumption falls over the 62-69 age range by 8.0 percent because of the reduction in benefits. Eliminating the earnings tax is predicted to have a substantial impact on labor supply, with average annual hours worked of married and single individuals between ages 62 and 69 predicted to increase by respectively 17 and 35 percent. Concomitantly, average net assets over that age range would increase by 8 and 21 percent for singles and married individuals. Finally, eliminating the option of early retirement is predicted to produce a comparable increase in average labor supply at ages 62 to 69 , but leads to a small fall (increase) in net assets for marrieds (singles).

An evaluation of these policies' impact on welfare and government revenue indicates that while a 50 percent benefit reduction and an increase in the normal retirement age to 70 both lead to comparable losses in welfare, the net revenue gain associated with the former is only 40 percent as large as that from the latter. An increase in the payroll tax rate to 15 percent also generates a lower revenue increase ( 75 percent of that of the benefit cut), but produces much smaller welfare losses, exemplifying the tradeoffs involved in policy makers' choice decisions.

The remainder of the paper is organized as follows. We present the model in the next section and the solution method used to solve the model in section 3. Section 4 describes the HRS data. The econometric specification and estimation method are discussed in section 5 . The auxiliary statistical model used for the indirect inference estimation procedure is presented in section 6 and details about the simulation methodology used to implement the procedure are provided in section 7. Estimation results and model fit are discussed in the following section and counterfactual experiments in section 9. A brief conclusion is presented in section 10 .

\section{Model}

The model represents the decision problem of an individual of given gender or a married couple. The optimization problem, consistent with the data available for estimation, begins at a point in the middle of the household's life cycle. Initial conditions are those that prevail at that life cycle point; variation among agents in initial conditions are not explicitly considered until the model's solution and estimation method are discussed.

\section{A. Choice Set}

An unmarried individual of gender $\mathrm{j}(\mathrm{j}=\mathrm{m}, \mathrm{f})$ at each discrete age a chooses consumption, $\mathrm{C}_{\mathrm{a}}^{\mathrm{j}}$, and hours worked in the labor market, $\mathrm{h}_{\mathrm{a}}^{\mathrm{j}}$. Hours worked, if positive, is allowed to take on only two values, part-time hours $\left(h^{\mathrm{j}}=1\right)$ and full-time hours $\left(\mathrm{h}^{\mathrm{j}}=2\right)$. In addition, the

\footnotetext{
${ }^{2}$ The reader should keep in mind that these policy changes are conducted in a partial equilibrium setting on a limited and quite selective subset of the population. Analyzing these changes if they were implemented for the entire population would require careful attention to their effects on different segments of the population and to labor market equilibrium effects on market wages.
} 
employment decision is constrained by whether or not the individual worked in the previous period; an individual who was working at age a-1 may choose not to work at age a, to work at age $\mathrm{a}$ in the old firm, $\mathrm{h}^{\mathrm{jo}}$, or to work in a new firm, $\mathrm{h}^{\mathrm{j}}$. An individual who did not work in the previous period must work, if at all, in a new firm. Employment choices are further restricted in that all individuals are assumed to stop working (permanently) at age $\mathrm{A}^{*}$. Consumption decisions are made until $\mathrm{A} .{ }^{3}$ Thus, the choice set at age $\mathrm{a}<\mathrm{A} *$ for an individual who worked in the previous period consists of all feasible combinations of $\mathrm{C}_{\mathrm{a}}^{\mathrm{j}}, \mathrm{h}_{\mathrm{a}}^{\mathrm{jo}}, \mathrm{h}_{\mathrm{a}}^{\mathrm{j}}$; for an individual who did not work in the previous period the choice set consists of the feasible combinations of $\mathrm{C}_{\mathrm{a}}^{\mathrm{j}}, \mathrm{h}_{\mathrm{a}}^{\mathrm{jn}}$. 4 The choice set at age a is denoted by $\mathrm{D}_{\mathrm{a}}^{\mathrm{j}}$ and a specific choice within that set by $\mathrm{d}_{\mathrm{a}}^{\mathrm{j}}$. A married couple chooses the consumption and hours of work of each; the choice set is given by $\mathrm{D}_{\mathrm{a}}^{\mathrm{mf}}=\mathrm{D}_{\mathrm{a}}^{\mathrm{m}} \times \mathrm{D}_{\mathrm{a}}^{\mathrm{f}}$ and any choice element within the set by $\mathrm{d}_{\mathrm{a}}^{\mathrm{mf}}$. Households, singles or couples, are assumed to be able to borrow and lend, and thus may smooth consumption over the life cycle, although net borrowing is restricted (see below). Net assets carried over from a (to $\mathrm{a}+1$ ), $\mathrm{W}_{\mathrm{a}+1}$, is determined residually from the consumption and labor force status decision at a. Consumption, and thus net assets, is treated as continuous.

\section{B. Preferences}

Each individual of gender $\mathrm{j}$ is assumed to have a well-defined preference function over own consumption and labor force status, namely $\mathrm{U}_{\mathrm{a}}^{\mathrm{j}}=\mathrm{U}^{\mathrm{j}}\left(\mathrm{C}_{\mathrm{a}}^{\mathrm{j}}, \mathrm{h}_{\mathrm{a}}^{\mathrm{j}} ; \mathrm{M}_{\mathrm{a}}^{\mathrm{j}}, \mathrm{Z}_{\mathrm{a}}^{\mathrm{j}}, \varepsilon_{\mathrm{a}}^{\mathrm{cj}}, \varepsilon_{\mathrm{a}}^{\mathrm{hj}}\right)$ where $\mathrm{M}$ is an indicator of marital status, $\mathrm{Z}$ is an indicator of health, and the $\varepsilon$ 's are age-varying shocks to the marginal utility of consumption and to hours worked. The marriage decision is not explicitly modeled. The decision model is assumed to pertain only to ages at and beyond some age $\mathrm{a}_{0}$, from which time it is assumed that an unmarried individual will forever remain single. A married individual may, however, become single after that age due to the death of the spouse, but may not remarry. ${ }^{5}$

1. Single Individuals-An individual who is single at some age $a, a \geq a_{0}$, having been single up to age a, or having been previously married but currently widowed, maximizes the expected present discounted value of remaining lifetime utility. The time of death is uncertain, although there is a known finite maximum length of life, $a=A$. Individuals are assumed also to obtain utility from bequests. The utility obtained from making a bequest if the individual were to die at age a is $\mathrm{B}_{\mathrm{a}-1}^{\mathrm{j}}\left(\mathrm{W}_{\mathrm{a}}\right)$. As the notation indicates, although the bequest actually occurs at a, the utility associated with the bequest is derived while the individual is still alive, at $\mathrm{a}-1$. An individual receives utility from the knowledge that a bequest would be made at a if the individual were not to survive past $\mathrm{a}-1$.

In the last potential decision period, at age $\mathrm{A}-1$, the individual's total utility is therefore $\mathrm{U}_{\mathrm{A}-1}^{\mathrm{j}}+\mathrm{B}_{\mathrm{A}-\Gamma^{\mathrm{j}}}^{\mathrm{j}}{ }^{6}$ Given the state space at $\mathrm{A}-1, \Omega_{\mathrm{A}-1}^{\mathrm{j}}$ (see below), the individual chooses the level of consumption, and thus net assets carried forward, that maximizes this terminal period total utility, i.e., $d_{A-1}^{j}=d_{A-1}^{j}\left(\Omega_{A-1}^{j}\right)$. Thus, the maximized value of each of the two components of total utility at $A-1$ can be written as a function of the state space. We denote the

\footnotetext{
${ }^{3}$ In the estimation, we set $\mathrm{A}=90$ and $\mathrm{A}^{*}=75$.

${ }^{4}$ There are five possible hours combinations in the first case, given that working in a new firm and in an old firm are mutually exclusive alternatives, and three in the second.

${ }^{5}$ We do not allow for divorce. However, divorce rates among individuals over the age of 50 are low. For example, in 1990, the number of divorces per 1000 married individuals age 50-54 was 12.0 for men and 8.2 for women. For married individuals age 60-64, the figures were 4.7 and 2.9. (Source: Monthly Vital Statistics Reports, Vol 43 No 9(S), March 1995).

${ }^{6}$ At ages prior to $\mathrm{A}-1$, the bequest is multiplied by the probability of not surviving to the next period. At all ages, the bequest is not discounted because, as noted, utility is received during the last period of life.
} 
maximized value of the first component of utility by $\mathrm{G}_{\mathrm{A}-1}^{\mathrm{j}}\left(\Omega_{\mathrm{A}-1}^{\mathrm{j}}\right)$ and that of the second (bequest) component as $\mathrm{Q}_{\mathrm{A}-1}^{\mathrm{j}}\left(\Omega_{\mathrm{A}-1}^{\mathrm{j}}\right)$.

At any age a, the maximized expected present value of remaining total lifetime utility given the state space at a, denoted by $\mathrm{V}_{\mathrm{a}}^{\mathrm{j}}\left(\Omega_{\mathrm{a}}\right)$, is the sum of the maximized expected present values of the remaining utility associated with the two components, $G_{a}^{j}\left(\Omega_{a}^{j}\right)$ and $Q_{a}^{j}\left(\Omega_{a}^{j}\right)$. Note that at age $\mathrm{a}<\mathrm{A}^{*}$, the choice set includes labor supply. Each of these components satisfy a Bellman equation, as does their sum. Specifically,

$$
\begin{aligned}
& \mathrm{V}_{\mathrm{a}}^{\mathrm{j}}\left(\Omega_{\mathrm{a}}\right)=\mathrm{G}_{\mathrm{a}}^{\mathrm{j}}\left(\Omega_{\mathrm{a}}^{\mathrm{j}}\right)+\mathrm{Q}_{\mathrm{a}}^{\mathrm{j}}\left(\Omega_{\mathrm{a}}^{\mathrm{j}}\right) \\
& =\max _{\mathrm{D}_{\mathrm{a}}^{\mathrm{j}}}\left\{\mathrm{U}_{\mathrm{a}}^{\mathrm{j}}\left(\Omega_{\mathrm{a}}^{\mathrm{j}}\right)+\delta \pi_{\mathrm{a}}^{\mathrm{sj}} \mathrm{E}\left(\mathrm{G}_{\mathrm{a}+1}^{\mathrm{j}}\left(\Omega_{\mathrm{a}+1}^{\mathrm{j}}\right) \mid \Omega_{\mathrm{a}}^{\mathrm{j}}, \mathrm{d}_{\mathrm{a}}^{\mathrm{j}}\left(\Omega_{\mathrm{a}}^{\mathrm{j}}\right)\right)+\left(1-\pi_{\mathrm{a}}^{\mathrm{sj}}\right) \mathrm{B}_{\mathrm{a}}^{\mathrm{j}}\left(\mathrm{W}_{\mathrm{a}+1}\left(\Omega_{\mathrm{a}}^{\mathrm{j}}\right)\right)+\delta \pi_{\mathrm{a}}^{\mathrm{sj}} \mathrm{E}\left(\mathrm{Q}_{\mathrm{a}+1}^{\mathrm{j}}\left(\Omega_{\mathrm{a}+1}^{\mathrm{j}}\right) \mid \Omega_{\mathrm{a}}^{\mathrm{j}}, \mathrm{d}_{\mathrm{a}}^{\mathrm{j}}\left(\Omega_{\mathrm{a}}^{\mathrm{j}}\right)\right)\right\} \\
& =\max _{\mathrm{D}_{\mathrm{a}}^{\mathrm{j}}}\left\{\mathrm{U}_{\mathrm{a}}^{\mathrm{j}}\left(\Omega_{\mathrm{a}}^{\mathrm{j}}\right)+\left(1-\pi_{\mathrm{a}}^{\mathrm{sj}}\right) \mathrm{B}_{\mathrm{a}}^{\mathrm{j}}\left(\mathrm{W}_{\mathrm{a}+1}\left(\Omega_{\mathrm{a}}^{\mathrm{j}}\right)\right)+\delta \pi_{\mathrm{a}}^{\mathrm{sj}} \mathrm{E}\left(\mathrm{V}_{\mathrm{a}+1}^{\mathrm{j}}\left(\Omega_{\mathrm{a}+1}^{\mathrm{j}}\right) \mid \Omega_{\mathrm{a}}^{\mathrm{j}}, \mathrm{d}_{\mathrm{a}}^{\mathrm{j}}\left(\Omega_{\mathrm{a}}^{\mathrm{j}}\right)\right)\right\},
\end{aligned}
$$

where $\pi_{\mathrm{a}}^{\mathrm{sj}}$ is the one-period survival rate (from a to $\mathrm{a}+1$ ) for a person of gender $\mathrm{j}$ and $\delta$ is the discount factor.

2. Married couples-In considering the objective function of married couples, to avoid notational complexity, assume that the husband and wife are of the same age. Then, if each is alive at age $\mathrm{A}-1$, the couple chooses consumption levels and hours of work of each to maximize a weighted average of the individual expected values of the remaining lifetime utilities. Specifically, letting $\theta$ be the weight placed on the husband's utility,



where $\Omega_{\mathrm{A}-1}^{\mathrm{mf}}$ denotes the state space for a couple, i.e, the Cartesian product of the individual state spaces. In general, the weight in any period would be, as written, a time-varying function of the current period state space.

In decision periods prior to $\mathrm{A}-1$, the couple takes into account the possibility that either or both may not survive into future periods. The expected present discounted value of the couple's remaining lifetime utility is given by

$\mathrm{V}_{\mathrm{a}}^{\mathrm{mf}}\left(\Omega_{\mathrm{a}}^{\mathrm{mf}}\right)$

$$
\begin{aligned}
& =\max _{\mathrm{D}_{\mathrm{a}}^{\mathrm{mf}}}\left\{\theta \mathrm{U}_{\mathrm{a}}^{\mathrm{m}}\left(\Omega_{\mathrm{a}}^{\mathrm{mf}}\right)+(1-\theta) \mathrm{U}_{\mathrm{a}}^{\mathrm{f}}\left(\Omega_{\mathrm{a}}^{\mathrm{mf}}\right)+\pi_{\mathrm{a}}^{\mathrm{sf}} \pi_{\mathrm{a}}^{\mathrm{sm}} \delta \mathrm{E}\left(\mathrm{V}_{\mathrm{a}+1}^{\mathrm{mf}}\left(\Omega_{\mathrm{a}+1}^{\mathrm{mf}}\right) \mid \Omega_{\mathrm{a}}^{\mathrm{mf}}, \mathrm{d}_{\mathrm{a}}^{\mathrm{mf}}\right)+\left(1-\pi_{\mathrm{a}}^{\mathrm{sm}}\right)\left(1-\pi_{\mathrm{a}}^{\mathrm{sf}}\right)\left[\theta \mathrm{B}_{\mathrm{a}}^{\mathrm{m}}\left(\mathrm{W}_{\mathrm{a}+1}\left(\Omega_{\mathrm{a}}^{\mathrm{mf}}\right)\right)+(1-\theta) \mathrm{B}_{\mathrm{a}}^{\mathrm{f}}\left(\mathrm{W}_{\mathrm{a}}\right.\right.\right. \\
& \left.\mathrm{d}_{\mathrm{a}}^{\mathrm{mf}}\right) \\
& +(1-\theta) \delta \mathrm{E}\left(\mathrm{V}_{\mathrm{a}+1}^{\mathrm{f}}\left(\Omega_{\mathrm{a}+1}^{\mathrm{f}}\right) \mid \Omega_{\mathrm{a}}^{\mathrm{mf}}\right. \\
& \left.\left.\mathrm{d}_{\mathrm{a}}^{\mathrm{mf}}\right)\right]+\left(1-\pi_{\mathrm{a}}^{\mathrm{sf}}\right) \pi_{\mathrm{a}}^{\mathrm{sm}}\left[(1-\theta) \mathrm{E}\left(\mathrm{Q}_{\mathrm{a}+1}^{\mathrm{f}}\left(\Omega_{\mathrm{a}+1}^{\mathrm{m}}\right) \mid \Omega_{\mathrm{a}}^{\mathrm{mf}}, \mathrm{d}_{\mathrm{a}}^{\mathrm{mf}}\right)+\theta \delta \mathrm{E}\left(\mathrm{V}_{\mathrm{a}+1}^{\mathrm{m}}\left(\Omega_{\mathrm{a}+1}^{\mathrm{m}}\right) \mid \Omega_{\mathrm{a}}^{\mathrm{mf}}, \mathrm{d}_{\mathrm{a}}^{\mathrm{mf}}\right)\right],
\end{aligned}
$$


where the argument, $\Omega_{\mathrm{a}}^{\mathrm{mf}}$, has been suppressed in $\theta$ and in $\mathrm{d}_{\mathrm{a}}^{\mathrm{mf}}$ for convenience. ${ }^{7}$ The value function in (3) is the sum of (i) the share-weighted average of the current individual utilities; (ii) the probability that they both survive times the couple's expected remaining lifetime utility one-period ahead; (iii) the probability that neither the husband nor the wife survives beyond the period times the share-weighted average of their individual utilities from a bequest; (iv) the probability that the wife survives beyond the period but the husband does not, multiplied by the sum of the husband's share times his expected utility of the bequest that the wife will make upon her death (which depends on her future savings decisions) and the wife's share times her expected remaining lifetime utility as a single individual; and (v) the probability that the husband survives beyond the period but the wife does not, multiplied by the sum of the wife's share times her expected utility of the bequest that the husband will make upon his death (which depends on his future savings decisions) and the husband's share times his expected remaining lifetime utility as a single individual.

If the husband and wife are of different ages, the Bellman equations are combinations of (1) and (3). Specifically, if the age difference is k periods, then from the younger spouse's age $\mathrm{A}-\mathrm{k}$ to age $\mathrm{A}-1$, the value function will be that of a single person as in (1). At the younger spouse's age $\mathrm{A}-\mathrm{k}-1$, when the older spouse is age $\mathrm{A}-1$, the value function for the couple will be given by (3) with the survival probability of the older spouse set to zero. In periods prior to the previous one, the value function is given exactly by (3).

\section{Budget Constraint}

Define $y_{a e}^{j}$ to be the amount of labor market earnings at age a of an individual of gender $j$ and $y_{\text {an }}^{j}$ the amount of non-earned income. Labor market earnings is the product of the hourly wage, $\omega_{\mathrm{a}}^{\mathrm{j}}$, and hours worked. Net earnings, $\tilde{y}_{\mathrm{ae}}^{\mathrm{j}}$, is labor market earnings net of the payroll tax and the income tax. The payroll tax rate is $\tau^{\mathrm{s}}(=7.65 \%$ in 1992) and is applied to earnings up to a maximum of $y_{e}^{\max }(=\$ 55,500$ in 1992). Non-labor income at age a is the sum of interest income (payments) on net assets carried over from the previous period, $\mathrm{rW}_{\mathrm{a}}$, where $r$ is the fixed (borrowing and lending) rate of interest, and retirement income from social security, $\mathrm{S}_{\mathrm{a}}^{\mathrm{j}}$, and from a private defined benefit pension on a previous job, $\mathrm{P}_{\mathrm{a}}^{\mathrm{j}} .8$ Labor earnings, interest income and pension income are also to be taxed at a constant marginal rate, $\tau^{\mathrm{y}}(=15 \%)$. In addition to a homogenous consumption good, the budget constraint also incorporates expenditures that arise from poor health. Specifically, an individual in poor health at age $\mathrm{a}, \mathrm{Z}_{\mathrm{a}}^{\mathrm{j}}=0$, pays a cost of $\mathrm{c}_{\mathrm{z}}$ if the individual is not covered by health insurance; an individual in poor health who is covered by health insurance at age $a\left(\mathrm{hi}_{\mathrm{a}}^{\mathrm{j}}>0\right)$ is assumed to have no out-of-pocket expenses as is a person in good health, $Z_{a}^{j}=1$. Thus, the budget constraint for a single individual of gender $\mathrm{j}$ is

\footnotetext{
7n (3), the mortality hazards of the husband and wife are assumed independent. Later, we allow them to be correlated through assortative mating on unobservables.

8 Allowing for pension accrual on a current job with a defined benefit plan or savings associated with a defined contribution plan introduces significant complications in the solution and estimation of the model. As discussed below, we restrict our sample to be consistent with the model.
} 


$$
\begin{aligned}
\mathrm{C}_{\mathrm{a}}^{\mathrm{j}}+\mathrm{W}_{\mathrm{a}+1}^{\mathrm{j}} & =\omega_{\mathrm{a}}^{\mathrm{j}} \mathrm{h}_{\mathrm{a}}^{\mathrm{j}}[1 \\
& \left.-\tau^{\mathrm{s}}-\tau^{\mathrm{y}}\right]\left[\mathrm{I}\left(\omega_{\mathrm{a}}^{\mathrm{j}} \mathrm{h}_{\mathrm{a}}^{\mathrm{j}} \leq \mathrm{y}_{\mathrm{e}}^{\max }\right)\right]+[(1 \\
& \left.-\tau^{\mathrm{y}}\right) \omega_{\mathrm{a}}^{\mathrm{j}} \mathrm{h}_{\mathrm{a}}^{\mathrm{j}} \\
& \left.-\tau^{\mathrm{s}} \mathrm{y}_{\mathrm{e}}^{\max }\right]\left[\mathrm{I}\left(\omega_{\mathrm{a}}^{\mathrm{j}} \mathrm{h}_{\mathrm{a}}^{\mathrm{j}}>\mathrm{y}_{\mathrm{e}}^{\max }\right)\right]+(1+\mathrm{r}[1 \\
& \left.\left.-\tau^{\mathrm{y}}\right]\right) \mathrm{W}_{\mathrm{a}}^{\mathrm{j}}+\mathrm{S}_{\mathrm{a}}^{\mathrm{j}}+\left[1-\tau^{\mathrm{y}}\right] \mathrm{P}_{\mathrm{a}}^{\mathrm{j}} \\
& -\mathrm{c}_{\mathrm{z}}[1 \\
& \left.-\mathrm{Z}_{\mathrm{a}}^{\mathrm{j}}\right] \mathrm{I}\left(\mathrm{h}_{\mathrm{a}}^{\mathrm{j}}=0\right),
\end{aligned}
$$

where $\mathrm{I}(\cdot)$ is an indicator function equal to unity if the expression inside the parentheses is true and zero otherwise. Similarly, the budget constraint for a married couple is

$$
\sum_{j} C_{a}^{j}+W_{a+1}^{m f}=\sum_{j} \tilde{y}_{a e}^{j}+\left(1+r\left[1-\tau^{y}\right]\right) W_{a}^{m f}+\sum_{j} S_{a}^{j}+\left[1-\tau^{y}\right] \sum_{j} P_{a}^{j}-\sum_{j} c_{z}\left[1-Z_{a}^{j}\right]\left[I\left(h_{a}^{m}=0\right) \cdot I\left(h_{a}^{f}=0\right)\right] .
$$

Notice that in (5), if either spouse has employer provided health insurance, the household is assumed to be covered. ${ }^{9}$ The individual or couple also faces a borrowing constraint, namely that $\mathrm{W}_{\mathrm{a}+1} \geq \underline{\mathrm{W}}(\mathrm{a}+1)$, where the lower bound on net assets is a function of age and may be negative. There is also assumed to exist a publicly (or otherwise) provided guaranteed minimum level of consumption, $\underline{\mathrm{C}}$, for a single individual and twice that for a couple. An individual or couple becomes eligible for the transfer if minimum consumption is not feasible after paying off the interest on the debt and enough of the principal to meet the following period's net borrowing constraint. ${ }^{10}$

\section{Wage Offers}

Wage offers are the product of a skill rental price, $\rho$, and an individual's stock of human capital, K. ${ }^{11}$ An individual accumulates human capital through general work experience and work experience specific to a job (tenure). The rental price of human capital has a firmspecific component, $\phi$, that is constant over tenure within the firm and also differs between part- and full-time employment. The wage offered to an individual is thus

$$
\omega_{\mathrm{a}}^{\mathrm{j}}=\rho\left(\mathbf{h}_{\mathrm{a}}^{\mathrm{j}}, \phi\right) \mathrm{K}_{\mathrm{a}}^{\mathrm{j}}\left(\mathrm{E}^{\mathrm{j}}, \mathrm{H}_{\mathrm{a}}^{\mathrm{j}}, \mathbf{T}_{\mathrm{a}}^{\mathrm{j}}, \varepsilon_{\mathrm{a}}^{\omega}\right),
$$

where $\mathrm{E}$ is years of schooling (assumed fixed at the initial age), $\mathrm{H}_{\mathrm{a}}$ is cumulative hours worked up to age $\mathrm{a}, \mathrm{T}_{\mathrm{a}}$ is tenure as measured by the cumulative hours worked for the current employer up to age a and $\varepsilon_{\mathrm{a}}^{\omega}$ is a random shock to an individual's human capital at age a. As already noted, an individual who is working at a -1 receives a wage offer from the same firm as well as an offer from a new firm. The wage offer from the new firm differs from that of

\footnotetext{
${ }^{9}$ The treatment of health related factors is obviously simplified. Our purpose is to capture their essential features, while maintaining tractability. Other researchers model health factors in more detail, but compromise on the features related to retirement that we emphasize.

${ }^{10}$ An individual or couple for whom minimum consumption is not feasible, according to the above criterion, is relieved of the interest payment in that period as well as that part of the debt necessary to meet next period's borrowing constraint.


Regardless, $\rho$ is taken as given by the individual.
} 
the old firm in that tenure is zero at the new firm $(T=0)$, there is a new firm-specific component to the rental price for the individual's human capital stock $(\phi)$ and a different human capital $\operatorname{shock}\left(\varepsilon_{\mathrm{a}}^{\omega}\right)$.

\section{E. Social Security Income}

Individuals generally become eligible to apply for social security at age 62 . To be eligible for benefits at that age on the basis of one's own employment history requires that the individual has accumulated 40 quarters of covered earnings. In 1992, an individual accumulated one quarter for each $\$ 570$ of annual earnings (up to a maximum of 4 quarters). Benefits (the primary insurance amount or PIA), given eligibility, depend on an individual's average indexed monthly earnings (AIME) calculated on an annual basis. ${ }^{12}$ In calculating this average, there is a maximum amount for covered monthly earnings within a year, $\$ 4,625$ in 1992 ( $\$ 55,500$ annual earnings, the same as is maximum taxable earnings, $y_{e}^{\max }$ ), and the lowest five years of indexed earnings are dropped. Given that we observe an individual's AIME only in the middle of the life cycle, in order to avoid having to keep track of the entire history of earnings in updating the AIME from that first observation, it is assumed that the lowest five years of earnings that have already occurred will remain the lowest. ${ }^{13}$ The number of computation years used to calculate the AIME is the number of years since turning age 21. Thus, letting $\mathrm{e}_{\mathrm{a}}$ be the AIME at age a, the AIME is updated as follows:

$$
\mathrm{e}_{\mathrm{a}+1}=\left[\mathrm{e}_{\mathrm{a}} \cdot(\mathrm{a}-21-5)+\frac{1}{2} \min \left(\mathrm{y}_{\mathrm{ae}}, \mathrm{y}_{\mathrm{e}}^{\max }\right)\right] /[\mathrm{a}+1-21-5],
$$

where all earnings figures are divided by 12 to reflect the monthly basis of the AIME.

In order to avoid adding another choice variable, we do not model the decision to apply for social security. Instead, it is assumed that all individuals accept social security in the first year in which their benefit net of the earnings tax exceeds $25 \%$ of the benefit they would receive if they had zero earnings. Thus, an individual who would receive a social security benefit at age 62 of at least that amount is treated as if the individual had applied for social security at age $62 .{ }^{14}$ If the net benefit is less than this amount at age 62 , then the benefits obtainable at age 63 are augmented to reflect the actuarial fair adjustment. A similar procedure is followed for all subsequent ages.

Social security benefits are a piece-wise linear function of AIME. Specifically, gross benefits are determined by

$$
\begin{aligned}
S_{62}^{g} & =\gamma_{0} e_{62} & & \text { if } e_{62}<b_{1}, \\
& =\gamma_{1}+\gamma_{2}\left(e_{62}-b_{1}\right) & & \text { if } b_{1} \leq e_{62}<b_{2}, \\
& =\gamma_{3}+\gamma_{4}\left(e_{62}-b_{2}\right) & & \text { if } b_{2} \leq e_{62}<b_{3}, \\
& =\gamma_{5} & & \text { if } b_{3}<e_{62} .
\end{aligned}
$$

\footnotetext{
12 The index used to calculate the AIME is based on the national average of total wages.

${ }^{13}$ The AIME is obtained from the HRS restricted data.

${ }^{14}$ Our treatment of the application decision is unlikely to have a large impact on our estimates. Rust and Phelan (1997), Benitez-Silva and Heiland (2006), Gustman and Steinmeier (2002) and Coile et. al (2002) all find a strong tendency for people to claim benefits upon or shortly after retirement.
} 
Gross benefits are zero if the number of accumulated covered quarters at age 62 is less than $40, \mathrm{q}_{62}<40 . .^{15}$ Earnings above a minimum amount, $\overline{\mathrm{y}}$ (= \$7440 annually, \$620 monthly in 1992), are taxed at a $50 \%$ rate, so potential net benefits at age 62 are

$$
\begin{aligned}
\mathrm{S}_{62}^{\mathrm{n}} & =\mathrm{S}_{62}^{\mathrm{g}}-.5 \max \left[\mathrm{y}_{62, \mathrm{e}}-\overline{\mathrm{y}}, 0\right] \text { if } \mathrm{S}_{62}^{\mathrm{n}}>0 \\
& =0 \quad \text { otherwise. }
\end{aligned}
$$

Gross benefits increase by $6.67 \%$ up to age 65 for each year that the age of first receipt of benefits is postponed. ${ }^{16}$ After age 65 , gross benefits are increased by a variable amount ranging from $5 \%$ to $8 \%$ depending on the calendar year in which the individual reaches age $62 .{ }^{17}$ In addition, the earnings tax is reduced to $33.3 \%$ at age 65 and to zero at age 70 , and the minimum monthly earnings not subject to tax between age 65 and 69 increases to $\$ 850.18$

Married individuals may elect to collect benefits based upon either their own AIME or that of their spouse who is retired. At age 62, the gross benefits available using the spouse's AIME is $37.5 \%$ of the spouse's gross benefits. If the age of first receipt is postponed to 63, gross benefits are $41.7 \%$ of the spouse's gross benefits, if postponed to $64,45.8 \%$, and if postponed to 65 or later, $50 \%$.

Widowed individuals can collect on their spouse's earnings record at age 60. At age 60, gross benefits are $71.5 \%$ of their spouse's gross benefits, at age 61, 77.2\%, and at ages 62 through $65,82.9 \%, 88.6 \%, 94.3 \%$, and $100 \%$. At any time after reaching age 62 , a widow(er) may elect to switch to the gross benefits based on their own earnings record.

Given the forward-looking nature of the model, it is necessary to make an assumption about what individuals forecast about future social security rules. We model this uncertainty as a discrete probability distribution over a fixed number of possible proportionate changes in benefits, i.e., proportionate changes in the parameters of the piece-wise linear components, the $\gamma$ 's, of the social security rule (8). ${ }^{19}$ Specifically, for any given AIME, benefits are forecasted to change proportionately by 0,25 , or $50 \%$ with given probabilities. We allow only one change to be forecasted by the individual up to age 62 which will be in place from then on. For a couple, the one change would have to occur by age 62 for the older spouse. ${ }^{20}$

\section{F. Mortality Risk}

Mortality is exogenous in the model, although the risk of mortality at any given age depends on an individual's state of health, sex and age. Specifically, the probability that the individual survives to age a+1 given survival to age a, the survival hazard, is

$$
\pi_{\mathrm{a}+1}^{\mathrm{sj}}=\pi^{\mathrm{s}}\left(\mathrm{Z}_{\mathrm{a}}, \mathrm{j}, \mathrm{a}\right)
$$

\footnotetext{
${ }^{15}$ In 1992, the values of the parameters determining benefits were as follows: $\gamma_{0}=.9, \gamma_{1}=348.3, \gamma_{2}=.32, \gamma_{3}=971.0, \gamma_{4}=.15, \gamma_{5}=1068.8$, and $b_{1}=387, b_{2}=2333, b_{3}=2985$, The latter set of parameters are referred to as bend points.

16 If benefits are collected prior to age 65 , the reduction in benefits continues past age 65 , although it is recalculated at age 65 to account for months in which net benefits were zero. We ignore this recalculation in the model and its associated incentive effects (see Benitez-Silva and Heiland, 2006).

${ }^{17}$ An individual reaching age 62 in 1993 or 1994 receives an adjustment to gross benefits of 5\%, with the adjustment increasing by . $5 \%$ for each additional two years up to $8 \%$ for individuals reaching age 62 on or after 2005 . In the model, we assume a constant, $5.0 \%$, rate for all birth cohorts in order to avoid having to solve the optimization problem separately for each cohort.

${ }^{18}$ The earnings tax has recently been eliminated for ages 66 to 69 .

19 We assume that the recent change in the earnings test reducing the exemption age to 66 was unanticipated.

${ }^{20}$ In the case of a widow(er), if the one change that is permitted in the model has not occurred prior to the spouses's death and the widow(er) is under the age of 62 , then the widow(er)'s expectation would be in force until reaching age 62 .
} 
for $\mathrm{j}=\mathrm{m}, \mathrm{f}$.

\section{G. Health}

An individual's state of health is assumed to affect utility directly as in (1) and mortality risk as in (10). As noted, health is assumed to be either good, $Z_{a}=1$, or poor, $Z_{a}=0$. The probability of being in good health at a +1 is assumed to depend on age, health at age a, and on whether the individual is covered by health insurance, namely

$$
\begin{aligned}
\pi_{\mathrm{a}+1}^{\mathrm{zj}} & =\pi^{\mathrm{z}}\left(\mathrm{a}+1, \mathrm{Z}_{\mathrm{a}}^{\mathrm{j}}, 1-\mathrm{I}\left(\mathrm{hi}_{\mathrm{a}}^{\mathrm{m}}=0\right) \cdot \mathrm{I}\left(\mathrm{hi}_{\mathrm{a}}^{\mathrm{f}}=0\right), \mathrm{j}\right) \text { if married } \\
& =\pi^{\mathrm{z}}\left(\mathrm{a}+1, \mathrm{Z}_{\mathrm{a}}^{\mathrm{j}}, 1-\mathrm{I}\left(\mathrm{hi}_{\mathrm{a}}^{\mathrm{j}}=0\right), \mathrm{j}\right) \text { if single. }
\end{aligned}
$$

The range of health insurance options is defined next.

\section{H. Health Insurance}

An individual can be covered by health insurance either through a job if one works, through a prior job that provides health insurance upon retirement, or automatically through Medicare upon reaching age 65 . We do not allow for the purchase of private health insurance nor do we distinguish between employer-provided insurance vs. Medicare in it's effect on health. Specifically, health insurance coverage at age a $(<65)$ is categorized as follows: $\mathrm{hi}_{\mathrm{a}}=2$ if the individual currently works or worked in the past for an employer who provide coverage that continues after retiring from the firm; $h_{\mathrm{a}}=1$ if the individual is covered by the employer who doesn't provide coverage after retiring from the firm; and $\mathrm{hi}_{\mathrm{a}}=0$ if the individual has no coverage. ${ }^{21}$

While at a particular firm, coverage, or lack of it, is assumed to continue without alteration until age 65 at which time Medicare coverage is substituted. We assume that new jobs do not provide coverage upon retirement, i.e., hi $\mathrm{a}_{\mathrm{a}} \in\{0,1\}$. A new employer may offer health insurance either only for full-time work or for both full- or part-time work. The probability that a new employer offers health insurance in either case is assumed to depend on the firmspecific component in the wage offer function, namely

$$
\pi_{\mathrm{a}_{T_{\mathrm{a}}=0}^{\mathrm{hi}}}^{\mathrm{hi}}=\pi_{\mathrm{a}}^{\mathrm{hi}}(\phi) .
$$

Conditional on receiving an offer from a firm that offers health insurance, the probability that the firm requires full-time work in the first year of employment to receive it is given by $\pi_{\mathrm{a}}^{\mathrm{hi}}(\cdot \mid \mathrm{hi})$.

\section{Solution Method}

The model is numerically solved by backwards recursion. However, because the state space consists of elements that are continuous variables, e.g., the current level of household assets and the current level(s) of the AIME, it is not possible to obtain "exact" solutions. Instead, we adopt an approximation method due to Keane and Wolpin $(1994,1997)$. The details of the solution procedure are provided for single individuals. The procedure for married couples differs only in the number of alternatives available to the household and in the size of the state space.

\footnotetext{
${ }^{21}$ As reflected in (5) and (11), we assume that the spouse of an individual with coverage is also covered.
} 
At age $\mathrm{A}-1$, a single individual decides on consumption to maximize terminal total utility, $\mathrm{V}_{\mathrm{A}-1}\left(\bar{\Omega}_{\mathrm{A}-1}, \tilde{\varepsilon}_{\mathrm{A}-1}\right)$, where the state space, $\Omega_{\mathrm{A}-1}$, is divided into a "deterministic" component containing the elements that are not random at the beginning of $\mathrm{A}-1, \Omega_{\mathrm{A}-1}$, and a "shock" component containing the vector of random shocks drawn at A-1, $\varepsilon_{\mathrm{A}-1}$. For any given value of the deterministic and shock components of the state space, optimal consumption is obtained by solving the Euler equation, allowing for one corner solution at the lower bound for net assets (implying a maximum level of consumption) and another at the minimum consumption level, for each of the three possible choices of employment status. The level of consumption that maximizes total utility is chosen for that value of the state space. At any deterministic state point, the expected value of maximum terminal utility is obtained by Monte Carlo integration, that is, by taking draws from the (joint) shock vector distribution and averaging to obtain $\operatorname{EV}_{\mathrm{A}-1}\left(\bar{\Omega}_{\mathrm{A}-1}\right)$. This expectation is calculated at a subset of the deterministic state points and the function is approximated for all other state points by a polynomial regression. ${ }^{22} \mathrm{We}$ denote this function as $\operatorname{Emax}(\mathrm{A}-1)$.

This procedure is repeated at age A-2. Using (1), substituting the $\operatorname{Emax}(\mathrm{A}-1)$ function for the future component of the value function at $\mathrm{A}-2$, the Euler equation is solved for optimal consumption. Monte Carlo integration over the shock vector at $\mathrm{A}-2$ provides $\mathrm{EV}_{\mathrm{A}-2}\left(\bar{\Omega}_{\mathrm{A}-2}\right)$ for a given deterministic state point. A polynomial regression over a subset of the state points provides an approximation to the function, denoted by $\operatorname{Emax}(\mathrm{A}-2)$. When age $\mathrm{A}^{*-1}$ is reached, the choice set is augmented to include the employment options and optimal consumption is determined at each potential employment choice. Monte Carlo integration over the shock vector at $\mathrm{A}^{*-1}$ provides $\mathrm{EV}_{\mathrm{A}^{*-1}}\left(\bar{\Omega}_{\mathrm{A}^{*-1}}\right)$ for a given deterministic state point. A polynomial regression over a subset of the state points provides an approximation to the function, denoted by $\operatorname{Emax}\left(\mathrm{A}^{*}-1\right)$. Repeating the procedure back to the initial age provides the Emax polynomial approximation at each age. The set of $\operatorname{Emax}(a)$ functions fully describe the solution to the optimization problem.

In the model described by (1) - (13), the state space for an unmarried (not widowed) individual of age a and gender $\mathrm{j}$ includes, in addition to a and $\mathrm{j}$, net assets $\left(\mathrm{W}_{\mathrm{a}}\right)$, health status $\left(\mathrm{Z}_{\mathrm{a}}\right)$ and health insurance status $\left(\mathrm{hi}_{\mathrm{a}}\right)$, work experience $\left(\mathrm{H}_{\mathrm{a}}\right)$, job tenure $\left(\mathrm{T}_{\mathrm{a}}\right)$ and the jobspecific wage component of the previous period's job $\left(\phi_{\mathrm{a}} \mathrm{I}\left(\mathrm{h}_{\mathrm{a}-1} \neq 0\right)\right)$, the AIME $\left(\mathrm{e}_{\mathrm{a}}\right)$, the number of covered quarters of social security $\left(\mathrm{q}_{\mathrm{a}}\right)$, whether the individual ever collected social security and if so the age at which benefit receipt began, whether a change in social security benefit rules has occurred and its magnitude, whether the individual retired from a pension job and is age-eligible to collect and if so, the amount currently collected $\left(\mathrm{P}_{\mathrm{a}}\right)$ and if not, the age at which the individual will be eligible to collect, and education (E). For a widow(er), the state space also includes the deceased spouse's AIME and the age at which the widow(er) is eligible to collect, and the deceased spouse's pension accrual and the age the spouse is eligible to collect. For married couples, all of the individual-specific components plus household net assets comprise the state space.

\section{Data}

The data come from the first three waves of the Health and Retirement Study (Juster and Suzman, 1995). The target population for the HRS in the 1992 first wave included all noninstitutionalized adults living in a household within the contiguous U.S. born in the years 1931-1941. Spouses of age-eligible individuals residing within the household are also HRS respondents. The HRS includes a representative core sample and oversamples of blacks,

\footnotetext{
${ }^{22}$ The approximation uses a spline function to capture the effect of the minimum consumption floor. After extensive experimentation, we found a piecewise quadratic specification with estimable nodes to be the best fitting. We used 20 draws for the Monte Carlo integration and 2000 state points for the approximation.
} 
Hispanics and Florida residents. A total of 12,652 individuals residing in 7,608 households were interviewed in 1992. The same households are re-interviewed every two years. A total of 11,596 individuals in 7,227 households were interviewed in 1994 and 10,964 individuals in 6,816 households in 1996.

The sample used in the analysis is restricted as follows:

1. Among those who were unmarried at wave 1 , those who were married by wave 2 or wave 3 were eliminated. Those women who were unmarried at wave 1 and widowed or divorced after age 44 were eliminated. ${ }^{23}$ Among those who were married at wave 1 , both household members were eliminated if the couple was divorced by wave 2 or wave 3 . We also restricted the sample to couples where the spouse of the HRS respondent was not less than 45 years old at the wave 1 interview.

2. We eliminated all individuals who were ever self-employed (through wave 3); in the case of married couples, both members were eliminated if either was ever selfemployed.

3. We eliminated all individuals who ever had defined contribution (DC) pensions; in the case of married couples, both were eliminated if either had a DC plan. ${ }^{24}$

4. We eliminated individuals who are currently working on a job with a DB pension and couples for whom that is the case for either. ${ }^{25}$

The estimation sample contains 230 single males, 363 single females, and 525 couples. $^{26}$ Table 1 provides descriptive statistics of the state variables at the initial wave for the estimation sample separately by gender and marital status. Single males and females in the HRS must come from the sampled birth cohorts; married males and females may be spouses of HRS respondents outside of the sample birth cohorts. The first number in each cell is the unweighted statistic (mean, percent), the number below in parentheses is the standard deviation and the number below that is the weighted statistic. ${ }^{27}$ Single respondents are on average around 56 years of age (weighted and unweighted). Because husbands tend to be older than their wives, and thus more likely to have been born before 1931, the average age of the married males in the sample is 59 and that of the married females, 55 (weighted and unweighted). ${ }^{28}$

As noted, blacks and Hispanics are oversampled in the HRS. The restrictions imposed in obtaining the estimation sample further skews the sample towards minorities, e.g., in the unweighted initial sample, 38 percent of single males and 19 percent of married males are

\footnotetext{
${ }^{23}$ The reason for this restriction is that the HRS did not collect social security records for spouses of those who are widowed or divorced. We adopt the implicit assumption that women who are widowed or divorced prior to age 45 will collect social security on their own earnings records.

${ }^{24}$ Allowing for savings from defined contributions plans would require adding another decision variable to the model given their taxdeferred treatment.

${ }^{25}$ Defined benefit plans are very heterogeneous with respect to their accrual rates and retirement age provisions. To incorporate DB plans would require that the model be solved for each individual in the sample with a different plan.

${ }^{26}$ The sample restrictions were made in the following way. The wave 1 sample consists of 12,652 individuals. Of those who were married at the wave 1 interview, 164 were divorced by wave 3 . Of the remaining $12,488,9,448$ were married at the wave 1 interview, 2,281 were single (not married or separated) and the rest were missing data on marital status. Of those who were married, for 2,869 couples (5,738 individuals), neither were ever self-employed. Of the singles, 1,826 were never self employed. Only 590 couples and 957 singles, 230 men and 627 women, satisfied the pension requirements of the sample ( 3 and 4 above). There were 525 couples where neither spouse was under age 45 . Of the 627 single women, 363 were either never married, or divorced or widowed prior to age 45 .

27 The weighted figures use the household weights supplied by the HRS. The weighted sample is representative of the population of households in 1992 for which at least one adult comes from the sampled birth cohorts.

${ }^{28}$ Using person weights, that is, giving positive weight only to those in the sampled birth cohorts, the weighted mean ages for married males and females, as they should be, are very close to those of their unmarried counterparts.
} 
black as opposed to 23 and 12 percent in the weighted estimation sample. Similarly, average completed schooling in the unweighted estimation sample is generally lower than for the weighted sample by as little as .3 years for single males and as much as .6 years for married males. Although the estimation sample does not contain individuals currently working in a job with a defined benefit pension, a significant proportion of the sample have previously held a job with a defined benefit plan (ranging from 17 percent for single females to 50 percent for married males). The average pension income being collected by married couples is $\$ 4,000 .^{29}$

The HRS collected a partial work history at the first interview. This included information about the beginning date of the current job, the beginning and ending date of the last job if not currently working, and the beginning and ending dates of jobs held more than five years. Respondents supplied information about hours worked and wages for those jobs. In addition, in wave 3 (1996), information was collected about the number of years worked six months or more and the number of those years consisting of full-time work. We used all of this information to calculate a measure of work experience at the time of the first survey. Specifically, we estimated the number of years the individual worked part- and full-time since the first year the individual worked at least six months. Total hours worked up to the initial interview is the number of part-time years times 1040 plus the number of full-time years times 2080. As seen in table 1, average work experience in the estimation sample ranges from about 32,000 hours for married females to 73,000 for married males. Single females had worked approximately 10,000 more hours than married females and single males about 15,000 hours less than married males.

Current job tenure follows a similar pattern, although the current tenure of single females exceeds that of single males. The fact that about 80 percent of the single females in the sample were previously married, albeit prior to age 45 , and during that time accrued less work experience, could account for their smaller work experience but slightly greater current tenure. Married males have current tenure of almost 14,000 hours and married females of around 8,000 hours.

The HRS collects detailed information on asset holdings at each wave. Table 1 reports statistics on total net assets at the first wave based on complete reports by respondents on all of the components of net assets and, separately, on total net assets that contains values imputed by the HRS for the components that are missing. ${ }^{30}$ Regardless of which measure is used, total net assets of single males exceeds that of single females and both are considerably less than the total net assets of married couples. For singles, the measure of mean assets that uses imputed values is about 50 percent higher for males and almost double for females than that of the measure without imputations. However, for married couples, the two measures of mean assets are close. Median net assets are considerably smaller than mean assets reflecting right skewness in the net asset distribution and, unlike for the mean, the median with imputations is about 50 percent higher than without imputations for married couples.

The number of quarters of covered earnings follows a pattern similar to work experience. Married males have on average the most covered quarters (108) followed by single males (93), single females (62) and married females (55). Commensurately, average indexed

\footnotetext{
${ }^{29}$ Among those actually collecting a pension, i.e., excluding those who never had a pension and those who are not yet collecting, the average for that same group is almost $\$ 12,000$.

30 Bracketed responses are included in the imputed category. These asset values do not contain an imputed value for social security "wealth" nor is it necessary to do so in defining the relevant state variable for the optimization problem.
} 
monthly earnings (AIME) is $\$ 1,276$ for married males, $\$ 931$ for single males, $\$ 499$ for single females and $\$ 390$ for married females.

Around 50 percent of single males and females report that their health is either fair or poor (what will be called "poor" health), while fair or poor health is reported by only about a third of married males or females. Among singles, 17 percent of the males and 21 percent of the females have employer-provided health insurance, while for married individuals the comparable rates are 18 percent for males and 11 percent for females. ${ }^{31}$ Only about 10 percent of individuals in the sample would have employer-provided health insurance available when retired, although that figure ranges from 6 to 12 percent across the groups.

Although not state variables of the model, the table also reports on responses in the first wave to several subjective expectations questions, asked of HRS respondents, that we make use of in estimation: the percent chance that the respondent will be working full-time after reaching age 62 , the percent chance that the respondent will survive to age 75 and to age 85 , and the percent chance that the respondent (or couple) will leave a bequest of $\$ 10,000$ or more, and separately, $\$ 100,000$ or more. According to these data, married males believe themselves slightly more likely to be working full-time after age 62 than single males, while (mean) percent chance of working full-time after 62 is 11 percentage points higher for single than for married females. ${ }^{32}$ Married males believe they are more likely to be alive at age 75 and 85 than singles, while there are only small differences between the beliefs of married and single females. Married individuals see themselves as more likely to leave a bequest of either 10,000 or 100,000 dollars. Expected social security benefits upon retirement are about the same for single males and females, although the current AIME is significantly larger for males, largest for married males and smallest for married females.

At each subsequent bi-annual interview, a fairly comprehensive job event history back to the previous interview is collected that includes beginning and ending dates of employerspecific job spells, and weekly hours worked and hourly wage rates at those dates. We used the data to create a monthly record of employment, weekly hours worked and hourly wages. Weekly hours worked within an employer spell is the average of the beginning and ending hours. The hourly wage during the employer spell is the weekly-hours weighted average of the hourly wage at those two points. Annual employment rates are calculated beginning at the month of the first interview and based on cumulating hours worked over each consecutive 12-month period; part-time employment in a year is defined as having worked between 500 and 1499 hours over the 12 months, full-time employment as having worked 1500 or more hours with non-employment the residual category. The hourly wage over the 12-month period is the average earnings over the period, the sum of earnings over employer spells in the 12-month period divided by total hours worked. Earnings over the period is the hourly wage times 1,040 if the individual worked part-time and 2,080 if full-time over the period.

We organized the data so that a decision period corresponds to a 12-month period. The first period observation is the 12-month period starting from the month of the first-wave interview, with each period corresponding to the subsequent 12 months. An individual's age in years over each 12-month period is the modal age in the period. Similarly, the calendar year is the modal year represented in a 12-month period. Households are observed for from one to five 12-month periods depending on the number and timing of the interviews in which they participated. Approximately 85 percent of the households are observed for at

\footnotetext{
31 In 27 percent of the married couples, at least one spouse had employer-provided health insurance.

${ }^{32}$ For earlier analyses of these expectations data see Honig $(1996,1998)$.
} 
least four 12-month periods, with less than 3 percent observed for 5 periods. Overall, there are 6,363 person-periods (4,313 household periods).

\section{Estimation Method}

The model represents the decision process of one household. Differences in the behavior of households with the same initial state variables arise solely due to iid shocks to preferences, shocks to health and health insurance coverage if changing jobs, and shocks to wages (conditional on the employer-specific unobservable for those who are working). However, behaviors tend to be more persistent than can be captured by observable state variables. We, therefore, allow for households to differ in some permanent features that are unobserved by us. Specifically, there are assumed to be a fixed number of types of people who differ parametrically in aspects of preferences and constraints. ${ }^{33}$ We provide the exact functional forms when we discuss the parameter estimates of the model.

There are two problems that arise in estimating the behavioral model. First, we observe decisions beginning only in the middle of the life cycle that are, thus, conditioned on state variables that arise from prior decisions. To the extent that those "initial" conditions are not exogenous, e.g., if there is unobserved heterogeneity in preferences or constraints, direct estimation will lead to bias. Second, a substantial number of observations in our sample are missing information necessary to calculate some of the initial state variables and some of the state variables are available only every other year. In particular, initial work experience could not be calculated for 32 percent of the males and 24 percent of the females and current job tenure for about 14 percent of males and 26 percent of females. In addition, at the first interview, total net assets (non-imputed) is missing for 50 percent, AIME for 30 percent and the number of covered quarters for about 24 percent of the sample.

To account for the "initial" conditions problem, we assume that the probabilities of the unobserved heterogeneity types can be represented by parametric functions of the initial state variables. With shocks to preferences, wages, etc., that are serially independent, the initial state variables are exogenous given type. In the case where observations are missing state variables, calculating choice probabilities (as would enter a likelihood function) would require integrating over the distribution of the missing state variables. ${ }^{34}$ To avoid that computational burden, we pursue a non-likelihood-based estimation strategy, indirect inference (see Gourieroux et al (1993), Gallant and Tauchen (1996), and Gourieroux and Monfort (1996)). The basic idea is to fit simulated data obtained from the behavioral model to an "auxiliary" statistical model that can be easily estimated and that provides a complete enough statistical description of the data to be able to identify the parameters of the behavioral model.

More specifically, we estimate a set of auxiliary statistical relationships with parameters $\Theta_{\mathrm{A}}$. At the ML estimate, $\hat{\Theta}_{\mathrm{A}}$, the score of the likelihood function (L) with respect to the actual

data $\left(\mathrm{y}_{\mathrm{A}}\right)$ must be zero, i.e., $\frac{\delta \mathrm{L}}{\delta \Theta_{\mathrm{A}}}\left(\mathrm{y}_{\mathrm{A}} ; \widehat{\Theta}_{\mathrm{A}}\right)=0$. Denoting $\Theta_{\mathrm{B}}$ as the parameters of the behavioral model, the idea is to choose parameters that generate simulated data $\left(\mathrm{y}_{\mathrm{B}}\right)$ that makes the score function as close to zero as possible. This is accomplished by minimizing the weighted squared deviations of the score function evaluated at the simulated data; thus the structural parameters are chosen such that

\footnotetext{
${ }^{33}$ This formulation of unobserved heterogeneity is common in DP models (see, for examples, Wolpin (1984), van der Klaauw (1995), Keane and Wolpin $(1997,2001)$ and Eckstein and Wolpin (1999)).

${ }^{34}$ Keane and Wolpin (2001) develop a likelihood simulation-based method of estimation when state variables are missing that circumvents having to perform that integration. The overall complexity of our model and data makes that method burdensome to implement.
} 


$$
\widehat{\Theta}_{\mathrm{B}}=\arg \min _{\Theta_{\mathrm{B}}} \frac{\delta \mathrm{L}}{\delta \Theta_{\mathrm{A}}}\left(\mathrm{y}_{\mathrm{B}}\left(\Theta_{\mathrm{B}}\right) ; \widehat{\Theta}_{\mathrm{A}}\right) \Lambda \frac{\delta \mathrm{L}}{\delta \Theta_{\mathrm{A}}}\left(\mathrm{y}_{\mathrm{B}}\left(\Theta_{\mathrm{B}}\right) ; \widehat{\Theta}_{\mathrm{A}}\right)
$$

The weighting matrix, $\Lambda$, that we have used is a block diagonal matrix, where each of the diagonal matrices is the inverse of the Hessian of an auxiliary model evaluated at the actual data. ${ }^{35}$ The estimator of $\Theta_{\mathrm{B}}$ is consistent when the number of simulated observations grows proportionately with the number of actual observations as the latter goes to infinity.

The auxiliary model that we use in estimation consists of a combination of "approximate" decision rules (that govern the choice variables) and modified structural relationships (such as the health transition function). Obviously, the choice of the auxiliary model is crucial for identification. It is, however, not possible to make a purely constructive identification argument.

\section{The Auxiliary Statistical Model}

The solution of the optimization problem of section II is a set of decision rules in which an optimal choice made at any age a (of a single individual or of the younger spouse) is a function of the state space at age a. As discussed above, all of the state variables at any age a enter into the decision rule that governs the choice at age a. To motivate one class of the auxiliary models, what we would call "approximate" decision rules, let $\mathrm{d}_{\mathrm{a}}^{\mathrm{k}}=1$ if alternative $\mathrm{k}$ is chosen at age a and zero otherwise, $\mathrm{V}_{\mathrm{a}}^{\mathrm{k}}\left(\Omega_{\mathrm{a}}^{\mathrm{k}}\right)$ be the expected discounted value of lifetime utility if alternative $\mathrm{k}$ is chosen (the alternative-specific value function), where $\Omega_{\mathrm{a}}^{\mathrm{k}}$ is the state space that is relevant to alternative $\mathrm{k}$, and $\mathrm{V}_{\mathrm{a}} \mathrm{k}\left(\Omega_{\mathrm{a}}^{\urcorner \mathrm{k}}\right)$ the maximum of the alternativespecific value functions excluding that of alternative $\mathrm{k} .{ }^{36}$ Decision rules take the form:

$$
\begin{array}{rlrl}
\mathrm{d}_{\mathrm{a}}^{\mathrm{k}} & =1 & \text { iff } & \mathrm{V}_{\mathrm{a}}^{\mathrm{k}}\left(\Omega_{\mathrm{a}}^{\mathrm{k}}\right)-\mathrm{V}_{\mathrm{a}}^{\neg \mathrm{k}}\left(\Omega_{\mathrm{a}}^{\urcorner \mathrm{k}}\right)=\mathrm{F}_{\mathrm{a}}^{\mathrm{k}}\left(\Omega_{\mathrm{a}}\right)>0 \\
& =0 & \text { otherwise. }
\end{array}
$$

Note that the decision rules depend on the entire state space, $\Omega_{\mathrm{a}}$, although individual value functions do not, and that the state space contains elements that are random from the researcher's perspective, e.g., preference shocks. Given the state variables that enter the model, to estimate approximate decision rules parametrically, then, requires choosing a function $\mathrm{F}$ and distributional assumptions for the shocks. ${ }^{37}$

When the choice set and/or the state space is large, approximate decision rules tend not to have parsimonious representations. The number of parameters to be estimated in any multinomial discrete choice statistical model will be at least equal to the number of state variables times the number of alternatives (less one). Recall that for an individual who did not work in the previous period, the choice set consists of consumption (or net assets) and 3 possible employment states (work full-time, work part-time or not work). For an individual who did work in the previous period, the choice set includes working full-time or part-time for the same or new employer as well as not working, 5 possible employment states. For married couples, the choice set is conditioned on the previous period's joint employment

\footnotetext{
${ }^{35}$ Tartari (2006) provides a derivation of the optimal weighting matrix for our case. We did not use the optimal weighting matrix because we were unable to invert the required outer product matrix.

${ }^{36}$ To illustrate, we assume that all of the decision variables are discrete. The general point is unaffected.

${ }^{37}$ See Keane and Wolpin (2000) for a more complete discussion of the formulation of approximate decision rules and for an application.
} 
state (both worked in the previous period, one worked but not the other, neither worked). If neither worked in the previous period, the couple has 9 employment choices, if one worked and not the other they have 15 choices and if both worked they have 25 choices. In addition, the couple decides on the consumption of each. With respect to the state space, the number of state variables, excluding the random (unobserved) state variables, exceeds ten for single individuals and twenty for married couples.

Missing state variables reduce substantially the sample sizes available for estimating the approximate decision rules. In estimating approximate decision rules, we include missing value dummy variables for all of the state variables as a means of maintaining sample size. We deal with both random and non-random non-response in the structural estimation of the model (see below).

Our goal in specifying auxiliary models is to maintain a reasonable degree of precision in the parameter estimates, while still providing enough score functions to achieve identification of the structural parameters. Therefore, we do not include all of the state variables in the approximate decision rules as dictated by the theory, and for that reason it is best to think of them as "restricted" approximate decision rules. On the other hand, to aid in identification, we include additional variables in the direct "structural" relationships. For example, we include variables not found in the structural wage offer function, in order to account for the fact that we observe only accepted wages, that is, wages for those who have chosen to work. Similarly, we include variables in the specification of health transitions that help to identify unobserved heterogeneity parameters, but that would otherwise not belong in the structural health transition function.

Through the 1996 wave, only about one-fifth of the HRS respondents in our sample had reached age 62 , the early social security retirement age. Counting the spouses of HRS respondents, the proportion reaching early retirement age is about three-tenths. Thus, the estimated incentive effects of the social security system on labor supply and savings would be, with this sample, to a great extent an extrapolation outside of the sample age range. To augment the information about behavior upon reaching age 62, we make use of subjective expectations questions available in the HRS. Respondents who were under the age of 62 and currently working were asked in each wave to report the percent chance that they would work full time after reaching 62 . In the context of the behavioral model, the answer to that question will be a function of the state variables at the time the question was asked. Similarly, additional information about asset accumulation is contained in questions concerning bequest propensities. Respondents were asked about the percent chance they would leave bequests exceeding 10,000 and 100,000 dollars.

An additional subjective expectations question used in the estimation is related to subjective mortality risk. As noted, the estimated mortality risk function is based on a small number of within-sample deaths. Extrapolating mortality risk to ages far out of the range of ages among those who died could be considerably inaccurate. Respondent reports of the percent chance of living to age 75 and to age 85 , are functions of the same state variables that enter the mortality risk function.

In the model, it was assumed that social security rules may be changed in the future. It would be difficult to identify the forecasts that people use simply on the basis of their behavior. However, respondents in the HRS are asked to report the amount of benefits they expect to receive when they retire. Since we know AIME and covered quarters, and the model provides a forecast of (the distributions of) future labor supply and wages, differences between the expected amount of social security and the amount forecasted by the model together will determine expectations about future changes in social security rules. 
The following comprise the set of auxiliary models used in estimation (the number of parameters is in parentheses, including missing value dummies): ${ }^{38}$

1. Multinomial logits of non-employment, full- and part-time employment: There are 29 separate multinomial logits ( 7 by each of four marital status - gender categories and one for couples only) using alternative sets of variables representing groups of variables such as age, health, social security status, net worth, and work experience (346 score functions). ${ }^{39}$ The union of the set of variables included in the specifications are: age (linear and age categories), race, education, lagged full-time work dummy, lagged part-time work dummy, cumulative hours worked, cumulative hours of tenure for current employer, health status, lagged health insurance coverage, number of quarters of covered earnings, AIME, amount of current private pension income, lagged net worth, dummy for age greater than or equal to $62 \times$ dummy for social security eligibility, the latter variable $\times$ AIME, age of spouse at least 62 , dummies for missing values of each of the above variables.

2. Multinomial logit of the transition from employment to non-employment, new or old employer: There are four separate specifications, one for each marital status and sex (34 score functions). The union of the set of variables included in the specifications are: age, lagged full-time work dummy, cumulative hours of tenure with current employer, lagged health insurance status, missing value dummies.

3. Regression of net worth : There are three specifications, one each for single males and females, and one for couples (27 score functions). The union of the set of variables included in the specifications are: double-lagged net worth, amount of current private pension income, cumulative hours worked, lagged full-time work dummy, lagged health status, race, spouse's education, spouse's AIME, spouse's lagged full-time work dummy, missing value dummies. ${ }^{40}$

4. Regression of log (accepted) wages: Four specifications, one for each marital status - gender category (51 score functions). The union of the set of variables included in the specifications are: lagged log wage, education, cumulative hours worked, cumulative hours of tenure, AIME, health status, lagged health insurance status, missing value dummies.

5. Logit regression of receiving versus not receiving health insurance in a new job: Four specifications, one for each marital status - gender category (28 score functions). The union of the set of variables included in the specifications are: education, full-time work dummy, AIME, cumulative hours of job tenure on previous job, missing value dummies.

6. Logit regression of health status transition: Four specifications, one for each marital status - gender category (37 score functions). The union of the set of variables included in the specifications are: education, AIME, race, cumulative hours of tenure, lagged full-time work dummy, double-lagged health status, missing value dummies.

\footnotetext{
${ }^{38}$ Because the auxiliary models do not represent behaviorally interpretable parameters, we do not present the auxiliary model estimates. They are available on request.

${ }^{39}$ We used these separate specifications rather than a single specification including all of the variables because we found the estimation algorithm to be more stable with specifications with smaller numbers of parameters.

${ }^{40}$ Recall that net asset stocks are collected at the time of each interview and are thus only available every two years. In the decision model, net worth collected at the 1992 interview is the state variable for 1992 decisions, assets collected at the 1994 interview reflect the 1993 consumption (and saving) decision and also serves as the state variable for 1994 decisions, and assets collected at the 1996 interview reflect 1995 consumption (and saving) and is the state variable for 1996 decisions. Thus, there are two years of asset choices, at the age corresponding to calendar years 1993 and 1995 . However, the asset state variables for these choices, assets at the start of 1993 and 1995, are not available, although assets two years prior, at the start of 1992 and 1994, are.
} 
7. Logit regression of mortality: One specification, marital status - gender categories combined (10 score functions). The variables included are: age, lagged health status, lagged health insurance status, race, dummies for marital status by gender, missing value dummies.

8. Regression of percent chance working full time after age 62: Four specifications, one for each marital status - gender category (45 score functions). The union of the set of variables included in the specifications are: education, lagged full-time work and lagged part-time work dummies, cumulative hours worked, cumulative hours of tenure, health status, current private pension income, missing value dummies. ${ }^{41}$

9. Regression of percent chance of leaving a bequest of $\$ 10,000$, of $\$ 100,000$ : Four specifications, one for each marital status - gender category (59 score functions). The union of the set of variables included in the specifications are: lagged net worth, education, AIME, health status, cumulative hours worked, spouse's education, spouse's health status, spouse's AIME, missing value dummies.

10. Regression of percent chance will live to 75 , to 85 : Four specifications, one for each marital status - gender category (44 score functions). The union of the set of variables included in the specifications are: age, health status, race, missing value dummies.

11. Regression of expected social security benefits Four specifications, one for each marital status - gender category ( 25 score functions). The union of the set of variables included in the specifications are: age expect to receive social security, AIME, cumulative hours worked, health status, missing value dummies.

\section{Simulating the Data}

At given parameter values and having solved the optimization problem (having computed the Emax functions), simulating one-step ahead decisions would be straightforward if all of the state variables were observed in each period. For example, consider a hypothetical individual who is 58 years old and unmarried as of the 1992 interview, and who is observed for five 12-month periods, i.e., through age 62. Given the state variables at the 1992 interview, a simulation of the decision at age 58 for that individual would be obtained by drawing a vector of contemporaneous shocks, for preferences, wages, etc., and choosing the alternative with the highest value function. Similar simulations could be obtained at ages 59-62 based on the actual state variables. If, for a particular draw of the mortality shock, the individual was simulated to have died, the simulation of that individual would cease at that point. Net assets at that point would determine the bequest.

A similar procedure would be followed for married couples. Given their ages in 1992, one would simulate the couple's choices based on their observed state space in each period. If one of them died, simulations would then proceed for the survivor as an unmarried individual based on a state space that carries forward their spouse's AIME. The bequest amount would be determined after both had died.

However, it is not possible to simulate a decision in a period in which a state variable is missing. If a state variable was missing randomly, one could apply an imputation method, say by drawing a value for the missing state variable from individuals matched according to some set of exogenous characteristics. One would then simulate the decision based on the state variables that are observed and the imputed state variable for that observation. A similar procedure could be followed if several state variables were missing.

\footnotetext{
${ }^{41}$ The error term in percent chance regressions includes classical measurement error.
} 
This procedure is problematic if state variables are not missing randomly. To account for biased non-reporting, the following modified imputation procedure can be used. For continuous state variables, such as net assets, AIME, work experience etc., it is assumed that the actual value of the state variable is given by the imputed value times a bias parameter that is estimated. ${ }^{42}$ It is this value of the state variable that is used to simulate the decision. For binary state variables, such as health status, lagged employment status or having forty or more quarters of covered earnings etc., again draw an imputed value. If it's a one (zero), estimate a parameter that determines whether it should have been a zero (one) and redraw a value from a uniform distribution that is used in the simulation. In our implementation, the bias parameter is set to zero for all state variables other than net assets. ${ }^{43}$

This procedure for simulating data assumes that the population is homogenous with respect to unobservables. As noted, we incorporate unobserved heterogeneity in the model by allowing for a finite number (two) of discrete types of individuals that differ in preferences and constraints. The probability that a simulated individual is a given type depends on the initial state variables, inclusive of imputed values modified for non-random reporting. ${ }^{44}$ Given that probability, each simulated observation is identified as a particular type by drawing from the type probability function.

It is useful to explain the procedure with a specific example. Consider a simplified version of the net worth auxiliary model ( 3 above) in which net worth is regressed only on net worth two periods before; as already noted, net worth is reported only every other year. There are four cases to consider: (1) net worth is reported at $t-2$ and at $t$; (2) net worth is reported at $\mathrm{t}-2$, but not at $\mathrm{t}$; (3) net worth is not reported at $\mathrm{t}-2$, but is reported at $\mathrm{t}$; (4) net worth is not reported at either $\mathrm{t}-2$ or at $\mathrm{t}$. The auxiliary model regresses net worth at $\mathrm{t}$ on two variables, net worth at $\mathrm{t}-2$ and a dummy variable equal to one if net worth is missing at $\mathrm{t}-2$ and zero otherwise; where net worth at $\mathrm{t}-2$ is set to some arbitrary number, say zero, if it's missing. ${ }^{45}$

In the first case, where net worth is observed at $\mathrm{t}-2$, we simulate the choices at $\mathrm{t}-1$, including net worth at period $\mathrm{t}-1$ (which is not observed in the data), update the state space and simulate the choices at $t$, including net worth at $t$. The simulated net worth at $t$ and the observed net worth at $\mathrm{t}-2$ enter into the score functions evaluated in equation (13). In case 2, because net worth at $t$ was not available to be used in the estimation of the auxiliary model, we do not use this observation (although we do have a simulated value of net worth at $t$ ) in (13). In the third case, we impute a net worth value at $t-2$, accounting for potentially biased non-response based on our estimate of the bias, simulate net worth through period $t$, and treat the observation as it was used in the auxiliary model. That is, we use the simulated value of net worth at $\mathrm{t}$, but treat net worth at $\mathrm{t}-2$ as missing. The last case is treated like the second because net worth at $t$ is missing.

Having simulated the data, the criterion function (13) is calculated for each of the auxiliary models. ${ }^{46}$ We iterate on the parameters using a simplex algorithm until the sum over the auxiliary models of (13) is minimized. The parameters include those of the behavioral

\footnotetext{
${ }^{42}$ The imputed values are obtained by drawing randomly from groups categorized by age, sex, race, schooling and marital status (as of the first interview). There are 36 groups for unmarried individuals and 54 for married individuals. For any given individual, because of sample size limitations, imputations for each state variable from the set of missing state variables are drawn independently.

43 Also, because so many state variables are missing in 1993 and 1995, we only use the actual (and imputed) state variables for 1992 and 1994. For 1993, we update the 1992 state variables by the 1992 decisions and the 1995 and 1996 state variables by the 1994 and 1995 decisions.

${ }_{44}^{4}$ Reporting bias for missing state variables is assumed not to vary by type.

${ }^{45}$ Clearly, this regression would provide no more information than one which throws out the observations with missing net worth at $\mathrm{t}-2$ if there were no other regressors with non-missing values.

${ }^{46}$ We perform 20 simulations for each sample observation, an individual or a couple, although we only draw a single imputed value for missing state variables.
} 
model, those of the type probability function and those defining the bias in missing state variables.

\section{Results}

\section{A. Parameter Estimates}

The functional forms of the model's structure are provided in appendix table A.1. Appendix table A.2 provides parameter estimates and associated standard errors. A number of the parameters are worth highlighting and provide some evidence about the credibility of the model. The coefficient of relative risk aversion $(1-\alpha)$ is estimated to be 1.678 for type 1 individuals and 1.591 for type two individuals, within the range of many other findings in the literature. ${ }^{47}$ These households are estimated to be severely borrowing constrained. The lower bound on net assets for single households is about $-6,400$ at age 50, falls to $-5,000$ at age 60 and to $-2,700$ at age 75 . For married household, the borrowing constraint is slightly less binding, about $-7,200$ for couples who are both 50 and $-3,100$ when they are both 75 . Interestingly, we estimate that mean reported assets are 25 percent lower due to selective non-reporting.

The estimates imply that consumption and leisure are substitutes $\left(\beta_{1}>0\right)$ and that the marginal utility of consumption increases with good health $\left(\beta_{2}>0\right) .{ }^{48}$ In addition, the marginal disutility of hours of work is greater for those in poor health $\left(\beta_{5}>0\right)$. Transiting from less to more work is costly, that is, the cost of transiting from not working to working part-time is less than transiting to working full-time $\left(\beta_{9}<\beta_{8}<0\right)$ and there is a cost to transiting from part-time to full-time work $\left(\beta_{12}>0\right)$. There is also a cost to changing jobs $\left(\beta_{10}<0\right)$, although it is significantly smaller than that of labor market entry. The disutility of working is lower for married individuals as the hours worked of the partner increases, that is, the leisure time of couples is complementary.

We restricted the state-space arguments of the Pareto weights to consist of the four combinations of husband and wife types and the difference between the husband's and wife's ages. ${ }^{49}$ Type 2 married women are estimated to have considerably less bargaining power than their husbands, while the Pareto weight for type 1 women is close to .5 regardless of the husband's type. In addition, the husband's bargaining power declines as the husband's age increases relative to his wife's age.

With respect to the estimates of the wage offer function, an additional year of schooling increases offered wages by 6.4 percent, wage offers peak at 54,500 hours of work experience (27 years of full-time work) and at 47,000 hours of tenure (23.5 years of fulltime work on the same job) and are 6.8 percent lower for blacks. We discuss the typespecific differences in wage offers below.

The survival hazard function is estimated primarily from the expectations question about survival chances to age 75 and 85 , although recall that a regression of actual deaths is also included among the auxiliary models. Previous work has shown that expectations data on

\footnotetext{
${ }^{47}$ Blau and Gilleskie (2005) report an estimate of 1.81, Rust and Phelan (1997) 1.07, Hurd (1989) 1.12, Blau and Gilleskie (2003) 0.95, French and Jones (2004) 2.97 and French (2005) between 2.2 and 5.1. See also Hubbard et. al. (1995).

${ }^{48}$ This finding is consistent with the findings of Gilleskie (1998) and Blau and Gilleskie (2003), but differs from that of Rust and Phelan (1997) who found it to be higher in poor health states.

${ }^{49}$ Separate identification of the Pareto weights and utility parameters potentially would be problematic, i.e., determined only by functional form assumptions, if the model were estimated solely on married couples. An essential identifying assumption is that utility parameters are the same for both single and married individuals, and so can be recovered from the behavior of singles, an assumption also exploited by Barmby and Smith (2000) and Browning et al. (2006). Although Pareto weights would generally depend on all of the elements of the state space, in order to conserve on parameters, we restricted the arguments of the weights to a few time-invariant elements.
} 
mortality risk are generally consistent with life tables. ${ }^{50}$ Because we allow for unobserved heterogeneity in the survival hazard function that is correlated with heterogeneity in other structural components of the model (for example, in the wage offer function) the parameters of the hazard function are jointly estimated with the other parameters of the model.

Qualitatively, we find that those in poor health, those without health insurance, males and blacks have higher mortality risk. Moreover, being in poor health together with having no health insurance further heightens mortality risk.

Quantitatively, our estimates of mortality hazards are not very different from life table estimates. Specifically, accounting for the distribution of poor health in our sample, the mortality risk at age 51 for males predicted from our model is .0058 , identical to the life table estimate. ${ }^{51}$ For males age 61 our prediction is .0139 compared to the life table figure of .0137. While these are remarkably close, the predictions for females is not as good. At age 51 our prediction is .0048 as compared to .0034 in the life table and at age $61, .1029$ as compared to $.0086 .{ }^{52}$ Poor health is predicted to have a large impact on mortality risk. At age 75 , men in poor health are predicted to have a mortality rate of .0885 , while those in good health have only a mortality rate of .0152 . The predictions for females are almost identical; the difference in mortality rates at that age, .048 for men and .031 for women from the life table, would arise solely from the greater incidence of poor health for men than for women. To account for the life table difference, 44.7 percent of men would have to be in poor health as compared to only 22.2 percent of women.

In the model, new jobs come with a wage offer, part of which is a firm-specific component, and may also come with a health insurance offer. We modeled the probability of receiving a health insurance offer as depending on an individual's current health and on the firmspecific component of the wage offer. Our estimates imply that the probability of receiving a job offer that includes health insurance (conditional on receiving an offer) is essentially invariant to the individual's health, .212 in either case. ${ }^{53}$ Although positive, the relationship between the firm-specific component of the wage offer and the probability of receiving health insurance is weak and the probability that a health insurance offer requires full-time work is 0.73 . In addition, having made job-to-job transitions over their life cycle, those who are currently working have a firm-specific component of their current wage that is on average 29.9 percent higher than the average firm-specific component of the offer that they would receive from a new firm.

\section{B. Model Fit}

Tables 2-9 provide evidence on the within-sample fit of the model as well as demonstrating other features of the data. These tables use the household weights and, thus, the figures are representative for the population of households with the selected characteristics of our estimation sample. ${ }^{54}$

\footnotetext{
${ }^{50}$ See Hurd and McGarry $(1995,2002)$.

${ }^{51}$ We use the Period Life Table, 2000 obtained from the Social Security Administration web site: www.ssa.gov/OACT/STATS/table4c6.html.

${ }_{52} \mathrm{We}$ have assumed that poor health occurs in our sample in the same proportion as in the population.

53 Dey and Flinn (2005), based on a continuous time model that was estimated with data from the 1996 SIPP find that 75 percent of wage offers for husbands were accompanied by employer-provided health insurance, while 57 percent of wage offers for wives were accompanied by wage offers. In their samples of individuals aged $20-54,80$ percent of husbands and 50 percent of wives were covered by their own insurance. Our estimate, an offer rate of $21 \%$ for both men and women, is considerably lower and corresponds to the much lower coverage rates of the older low-income population represented by our sample (Table 1).

${ }^{54}$ Model predictions are obtained by simulating choices for each single person ten times for each of the two types, and for each married couple five times for each of the four types. In comparing the simulated data sample statistics to the household weighted HRS data, the simulated observations are weighted by the product of their type proportions (to account for using the same number of simulated observations for each type) and the HRS household weights. Figures based on data without household weights are designated as unweighted in the tables.
} 
Table 2 reports non-employment rates by age for each marital status-gender group for the actual data and as predicted by the model, both for weighted and unweighted data. Because in a 12 month period, an individual will usually span two ages (in years), we present the data for those age 60 and above as two-year moving averages. Although this tends to smooth over abrupt changes, such changes are still generally apparent. For ease of presentation, we group together those age 50-59 and also those age 66 and over. It is more salient to concentrate on the weighted data because of their representativeness. Married males have by far the lowest average non-employment rate between ages 50-59, 37.5 percent, followed by single females at 51.1 percent, single males at 60.1 percent and married females at 63.2 percent. All groups increase their non-employment rates considerably in their 60's. Between age 60-61 and age 61-62, the first time some of them reach the social security early retirement age, non-employment rates increase by 7.5 percentage points for married males; similarly, between 61-62 and 62-63, when the rest of the sample also reaches 62 , the increase is by 5.5 percentage points. For married and single females, the combined increase between age 60-61 and 62-63 is 9 to 10 percentage points. However, there is essentially no increase for single males, although they had the largest increase between 50-59 and 60-61. The model fits the pattern for these groups reasonably well. For all groups, the model, however, understates the increase between 50-59 and 60-61 and tends to overstate the increase from 60-61 to 62-63. By age 64-65, the model corresponds quite well with the data for married males and single females, but overstates the non-employment rate for married females.

Tables 3 breaks down employment rates into full- and part-time. As seen, full-time employment rates decline almost monotonically for married males with age; there is a decline of 15.1 percentage points between ages $60-61$ and $62-63.55$ Over the same ages, there is a decline of 7.1 percentage points for married females. The model predictions are declines of 14.6 and 10.7 percentage points. For married males and females, part-time employment rates are roughly constant up to age 61-62 and then increase slightly for married males, while they decline slightly for married females. The model captures the increase for the married males, although not by as much, and captures the decline for females, although it is overstated.

The full-time employment rate for single males follows a u-shape. The model, while picking up the first large decline, predicts its continuation, rather than the increase. Instead, the model predicts a large increase in part-time employment at the last two age intervals. Following a large decline in full-time employment between 50-59 and 60-61, for single females there is a continuing decline through the age of early retirement eligibility and then a leveling off. The model captures this decline. As with single males, the model diverges from the data at the last two age groups, predicting a continued decline and an increase in part-time employment when neither occurs.

Tables 4 compares actual and predicted statistics for (accepted) full- and part-time wages by marital status and gender. It should be emphasized that the model estimates the structural wage offer distribution and that wages are observed only for those who have chosen to work. Matching full- and part-time employment rates and the full- and part-time accepted wage distribution is therefore challenging. As seen in table 4, the mean and median full- and part-time wages are greatest for married men, least for married women and similar for single males and females. The mean (accepted) full-time hourly wage for married males is three dollars more than for married females and two and a half dollars more than for single males

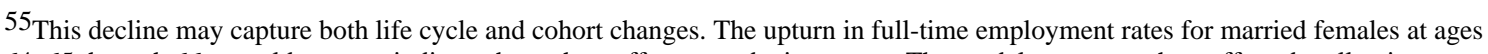
64-65 through 66+ would seem to indicate that cohort effects may be important. The model captures cohort effects by allowing type proportions to vary with initial (wave1) age.
} 
and females. Part-time wages are almost the same for all groups except married females, which are lower by almost 2 dollars per hour. Medians are lower than means, reflecting the usual right skewness, and standard deviations are generally large relative to the means. Predicted mean and median wages tend to be within about a dollar of the corresponding actual figures and are often much closer. The fit to the standard deviations is more variable.

It is obviously important that the model capture the major features of the net worth distribution. Tables 5 provide statistics on the actual and predicted distributions for married couples and for single men and women. The actual distribution of net worth within each group, as has been well documented and as seen in table 5, is quite disperse and heavily right-skewed. The mean level of net assets for married males in the weighted sample is $\$ 125,432$, with a standard deviation a bit more than one and a half times that amount and a median value about half that amount. Mean net worth is quite low for single men and women, $\$ 44,491$ for men and $\$ 32,876$ for women. Moreover, the median is only $\$ 1,650$ for men and $\$ 600$ for women. The large degree of inequality in net worth is clear from the table. As also shown net worth is higher for older married individuals in this population, but not for older single individuals. Importantly, there are generally only small differences in all marital-gender groups between the distribution of net worth generated by the model and the distribution in the data. The model not only fits well the mean and median, but also the $10^{\text {th }}$ and $90^{\text {th }}$ percentiles, as well as the age pattern.

Tables 6 presents actual and predicted employment transition rates, again by marital status and gender. Non-employment appears to be close to an absorbing state for all groups; yearto year transition rates to either full- or part-time employment from non-employment are only between one and three percent. The model captures much, but not all, of this permanence. Although the predicted transition rate out of non-employment is less than 10 percent for all groups, the model overstates transitions from non-employment to full-time employment. With respect to the employed states, between 85 and 90 percent of those employed full-time in any year tend to remain employed full-time in the following year, while about 60 percent of those working part-time make the same choice in the following period; single males are an exception with 45 percent. The model does not capture quite the same degree of permanence in full-time employment for any of the groups, the transition from full-time employment to the same state being between 69 and 77 percent. The model does better in capturing the permanence of part-time employment, except in the case of married women where it is understated and single men where it is overstated, and the model generally overstates transitions from part-time to full-time employment.

Table 7 reports on the model's fit to the expectations data. These variables are forecasted by averaging over the simulated lifetime sequences of choices and outcomes based on current state variables. Results are not unreasonable, if somewhat mixed. The model underpredicts the reported percent chance of working full-time after age 62 for males, by 12 percentage points for married males and by 9 percentage points for singles, and overpredicts it for married females, by 17 percentage points, but is within 0.1 percentage points for single females. The model fairly closely predicts the reported percent change of being alive at age 75 and 85 . With respect to anticipated bequests, the model overstates both the percent chance of leaving a bequest of 10,000 dollars and 100,000 dollars for all groups, generally by between 10 and 15 percentage points. Finally, the predicted expected social security amount is within one percent of the actual for married males, 16 percent too low for married males, 30 percent too low for single males and 47 percent too low for single females. Interestingly, the model's understatement is not due to its prediction of expectations held about the future of social security. We estimate that the individuals in our sample believe there will be no changes in the rules as it affects their benefits. 
Table 8 considers the joint labor supply of husband and wives. The table varies the husband's age while keeping the wife's age fixed between 50-59. Although wives age as the husband's age increases, the wive's increase, given the age restriction, is slower so that the age difference increases. The prevalence of couples who both work falls from 30.3 percent when the husband is between the ages of 50 and 59 to 13.8 percent when the husband is 60 or 61 . The fall in joint employment is almost entirely made up by an increase in the percent of couples in which neither work. The percent of married households in which both work continues to fall gradually with the husband's age, reaching 10.3 percent for couples in which the husband is 65 to 66 . On the other hand, as the husband ages beyond 60 , the percent of households in which only the husband works falls, from 28.8 percent when the husband is 60-61 to 7.5 percent when the husband is $64-65$. There is a concomitant small rise in the percent of households in which only the wife works, from 13.7 percent when the husband is $50-59$ to 20.8 percent when the husband is $64-65$, but the main shift is towards neither working. The model considerably understates the extent to which both are working when the husband is between 50-59, compensating by overstating the situation in which only the husband works. The model does reasonably well from age 60 on, capturing the overall movement from the situation in which only the husband is working to the one in which neither is working, albeit continuing to overstate the extent to which only husbands work. In the data, the proportion of couples in which only the husband works falls 23 percentage points between 50-59 and 64-65 and by 28 percentage points in the model. Similarly, the rise in proportion of couples in which neither works is almost identical in the data and in the model over these same ages.

Tables 9 compares actual and simulated labor supply choices for married and single individuals by several characteristics: whether or not they were receiving income from a private defined benefit pension in 1992, their current health status and their completed education. Employment differences in the data tend to be large. As already noted, those receiving income from a defined benefit private pension are much less likely to work and more likely to work part time if they work. A similarly larger proportion of those who report being in poor health are non-participants compared to those who do not report poor health. Employment differences between those who did not and those who did complete high school tend to be relatively small for married males and especially large for single females. All of these are features of the model as well.

Although not specifically related to model fit, tables 10 and 11 highlight the importance of accounting for unobserved heterogeneity. In the estimation, we allowed for two types for each sex. Thus, single individuals are one of two types, while married couples are of potentially four types. Our estimation reveals interesting differences in behaviors as well as important marital selectivity according to type. We estimate that 49.6 percent of males in the HRS birth cohort (those 51-61 in 1992) are of their sex-specific type 1 (50.4 percent are of type 2) and 69.5 percent of women are of their sex-specific type one (30.5 are of type 2). As the tables show, there is clearly marital selection by type. For males within the HRS birth cohort, 98.7 percent of those who are single are type one, while that's true of only 7.2 percent of those who are married (and married to a female in the HRS cohort). For females, 58.2 percent of those who are single and 80.6 percent of those who are married (to males in the HRS cohort) are type $1 .{ }^{56}$ Thus, type one males are over-represented and type one females are under-represented among singles.

Among singles, there is little variation in mean schooling levels by type; the difference is only .1 years both for males and females. There is considerably more variation among

\footnotetext{
56 The figures are only slightly different if we do not restrict the sample to married couples in which both are from the original HRS age cohort. For all married males in the sample, 16.0 percent are type 1 and for all married females, 79.3 percent.
} 
married couples. Mean schooling of couples in which both are type one is the highest for both spouses, 11.8 for men and 11.5 for women, and is the lowest for couples in which both are type 2,10.9 for men and 10.7 for women. There seems to be positive assortative mating on schooling across the four types. Single men differ only slightly by type in their labor supply, average net worth or average annual consumption. However, they do differ significantly in their annual earnings, which is almost entirely due to the fact that type 1 males receive lower wage offers than do type 2 males; as seen in table A.2, type 1 males receive a 40 percent lower wage offer than otherwise identical type 2 males. Single women differ to a greater extent by type than do single men. Only 20.9 percent of single women of type 1 engage in market work as compared to 84.6 percent of type 2 women. Because they participate so much less, the annual earnings of type 1 single women are about one-third as large as those of type 2 single women even though the wage offer to otherwise identical type 1 women (independent of marital status) is 37.7 percent lower (see table A.2). Type one women work much less because they have a much greater distaste for market work than do type 2 women (see table A.2).

This distaste for work of type 1 women shows up again among type 1 married women, regardless of the type of their husband. Only 14.6 percent of type 1 women work when coupled with type 1 men and only 6.5 percent work when coupled with type 2 men. About 70 percent of the husbands of each type work. On the other hand, type 2 married women participate more than their husbands, although these couples comprise only 19.4 percent of all married couples. These different labor supply patterns of husbands and wives show up in their relative annual earnings as well, with one exception. Husbands earn more than their wives in households where both are type 2 even though the wives participate about twice as much as their husbands. As with singles, this is due to the lower wage offer received by type two women, who also have a lower disutility of working than do their husbands (see table A. 2).

An interesting pattern in the share of household consumption emerges from our estimates. Type 1 wives, who contribute only a small amount to total household earnings ( 20 percent in one case and 6 percent in the other), share about equally in total household consumption, while type 2 wives, who contribute much more to total earnings (60 percent in one case and 47 percent in the other) receive less than a 20 percent share of total consumption. In addition to type 2 wives having lower disutility from working, as previously noted, type 2 wives have less bargaining power than do type 1 wives.

\section{Policy Experiments}

In this section, we first consider the effects on labor supply and savings of social security reforms that have been suggested as a means of bringing the system into financial balance. In this analysis we focus on a sample of households who would be most at risk from the types of changes in the social security program that have been proposed: households whose members are not currently, or anticipating, collecting on a defined benefit pension plan from a previous job. ${ }^{57} \mathrm{We}$ also highlight the impact of those reforms on other related outcomes, such as earnings, consumption, and social security take-up and benefits received. We then consider what would have been the effects on household welfare and social security budget savings for a subset of the reforms, if they had been implemented in 1992.

\footnotetext{
${ }^{57}$ Tables reporting the model fit for the no-pension sample (analogous to Tables 2-9 for the estimation sample) are available on request. While there are differences in the means, with net assets being considerably less for individuals in all marital status and gender groups, and with the mean level of schooling being 9.8 for the no-pension subsample, compared to 12.6 for the sample with a prior pension job, the model's ability to fit the data is comparable to that for the estimation sample.
} 


\section{Behavioral Implications}

Tables 12-14 provide estimates of the effect of altering social security program parameters for married couples (table 12), for single men (table 13) and for single women (table 14). Married couples are restricted to those in which both the male and the female fall within the age range 51 to 61 as of 1992, that is, to those married households in which both are in the HRS cohort. The first column in each table provides the baseline data. The effects are shown for two age categories: $51-61$ and $62-69.58$ In contrast to the previous tables in which predictions are made only for the estimation sample and condition on state variables observed in 1992 and 1994, these tables forecast behaviors outside of the estimation sample and are conditioned only on 1992 state variables. We will consider each programmatic change in turn, although we first consider the baseline predictions for the two age periods. ${ }^{59}$

Baseline Predictions-As seen in table 12, there is a significant reduction in the participation of both husbands and wives between the ages before and after social security eligibility (age 62); the non-employment rate increases from 27.0 to 48.7 percent for husbands and from 75.9 to 84.2 percent for wives. For husbands, the fall in the rate of fulltime work is actually larger than the increase in the non-employment rate by about 9 percentage points, reflecting an increase of that amount in the rate of part-time work (from 4.7 to 13.6 percent). Wives, on the other hand, do not, on average, transit from full-time employment to part-time work after reaching age 62. Overall, average annual hours worked falls by 37 percent for both husbands and wives, although husbands supply 3 times as many hours as their wives. Husband's take a larger share of total household consumption, 54 percent in the first age range and 57 percent in the second, and household consumption is 20 percent higher in the older than in the younger age range. Income from social security is almost 10,000 for the household. Net assets increase by 74 percent between the two age ranges.

Single males reduce their participation considerably less after eligibility than do their married counterparts. Indeed, the large fall in full-time employment (from 32.7 to 10.3 percent) is almost completely offset by the rise in part-time employment (from 10.2 to 31.7 percent). Overall, however, the fall in average annual hours of 31 percent, is comparable to married men. Average annual consumption is almost the same in the two age periods and significantly less than the married men. Income from social security is about 5,300 dollars per year, about half that of the married households. As with married households, net assets increase substantially over the periods, by 77 percent, although they are only about one-fifth that of married households.

Single females, as already noted, work more than married females and single men and the change in their labor supply after eligibility is also different. Like both single males and married females, single females reduce their full-time employment substantially (from 40.3 to 24.0 percent). However, unlike married females, they also increase their part-time employment (from 13.2 to 22.9), but not, as with single males, to the extent that it completely offsets the fall in full-time employment. Overall, the fall in average annual hours, of 24 percent, is smaller than that of either married females or single males. Average annual consumption is, like single males, almost constant across the periods and is larger than that of married females, although only slightly so in the later age period. Income from social security is about 3,000, considerably less than for single men because of a smaller take-up rate (in part because they have a higher full-time employment rate).

\footnotetext{
58 Married men are on average 57.6 and married women 56.7 years of age in the first age range; they are approximately 8 years older, 65.8 and 64.9, in the second age range. Single men are, on average, 57.9 and 65.3 in the two ranges and single women, 57.8 and 65.4. A table that breaks down the labor supply effect by finer age intervals is available upon request.

${ }^{59}$ As in the prior tables, the statistics from the simulations use household weights.
} 
Five policy experiments are performed: a reduction in benefits (separately by 25 and 50 percent), an increase in the employee payroll tax to 15 percent, the elimination of the earnings tax, eliminating the early retirement age (eligibility begins only at age 65) and raising the eligibility age to 70 (and no early retirement).

\section{Benefit Reduction}

Married couples: As seen in table 12, a 25 percent reduction in benefits slightly reduces participation of both husbands and wives in the 51-61 age range and increases their participation in the 62-69 age range. The change in the latter age range is much larger for husbands than for wives. Full-time employment of husbands increases by 7.4 percentage points, while part-time employment falls by 3.8 percentage points. Overall, average annual hours worked by husbands falls by 29 hours ( 2 percent) over the 51-61 age range, but increases by 116 hours ( 13 percent) over the 62-69 age range. The comparable changes for wives are 15 ( 3 percent) and 34 (12 percent) hours. Due to the changes in their labor supply, the average annual earnings of both spouses decrease when they are 51 to 61, by 267 dollars for husbands and by 116 dollars for wives, but increase by 1,173 dollars for husbands and 169 dollars for wives. The reduction in benefits thus leads to intertemporal substitution in annual hours - given forward looking behavior, married couples substitute slightly more leisure before eligibility for the reduced leisure after eligibility. The fact that the direction of the effect is the same for both husbands and wives reflects the leisure complementarity implied by our estimated utility parameters.

Average annual consumption for the household, the sum of consumption, falls in both periods, by 414 dollars ( 2.8 percent) in the 51-61 age range and by 708 dollars ( 4.0 percent) in the 62-69 age range. The fall in household consumption is shared fairly equally between the husband and wife; for example, in the 51-61 age range, the husband's consumption falls by 233 dollars ( 2.9 percent) and the wife's by 181 dollars ( 2.7 percent). The household's average net assets increase by a negligible amount before eligibility, but falls by 2.2 percent over the later age range. Thus, after gaining eligibility the household both increases its labor supply and reduces assets in order to make up for the consumption loss associated with the lower benefits. Although the lower benefits reduce the social security take-up rate by a small fraction, the fall in average monthly social security benefits received by the husband and wife, by 229 dollars or 28.0 percent, is almost entirely due to the benefit reduction.

All of the effects are magnified with a 50 percent reduction in benefits. Household labor supply increases by 310 hours per year (25 percent) over the 62-69 age range, with a concomitant increase in household earnings of over 3,000 dollars (27 percent). Net asset holdings fall by almost 4,000 dollars per year and consumption by 1,500 dollars. Average social security benefits fall by over 5,000 per year.

Single Males: A 25 percent reduction in benefits reduces participation by 3.1 percentage points in the 51-61 age range, coming both from a reduction in full- and part-time work. There is, surprisingly, also a small reduction in the participation rate in the 62-69 age range ( 0.2 percentage points). However, there is a shift towards full-time employment leading to an increase in annual average hours worked (from 543 to 588 hours, or 8 percent), reflecting, as with married couples, intertemporal substitution. Average annual consumption falls in both periods, by a little more in the second (3.8 percent in the first and 5.7 percent in the second age period). As with married couples, average net assets increases in the 51-61 age range (by 2.3 percent) and falls in the 62-69 age range (by 3.9 percent). All of these effects are magnified when benefits are reduced by 50 percent reduction.

Single Females: The effect of benefit reduction is qualitatively similar for single females. Intertemporal labor supply effects are present, leading to a near equalization of average 
annual hours in the two age period when benefits are reduced by 50 percent. Although consumption falls by more in the second period, the fall in income that occurs from the reduction in benefits, about 1,000 dollars for the 25 percent reduction, is significantly compensated for by the increased earnings.

\section{Increasing the payroll tax}

Married couples: Raising the payroll tax to 15 percent, as expected, increases nonemployment rates. As with benefit reductions, the effects are larger for husbands. The nonemployment rate increases by about 4.7 percentage points for husbands age 51-61 and by 6.8 percentage points for husbands age 62-69; average annual hours fall by 94 hours ( 6 percent) in the first age range and by about 149 (16 percent)in the second. Concomitantly, the household's average annual earnings falls by 5.4 and 15.3 percent. Household annual average consumption falls by 8.1 percent at the earlier ages and by 7.7 percent at the later ages, while average net assets falls by 5.0 and 7.6 percent. Average social security benefits actually rises, though only by a small amount, because of the higher take-up rate induced by the additional work disincentive.

Single Males: The greater disincentive to work caused by raising the payroll tax increases the rate of non-employment for single males even more than for married males. Average annual hours falls by 17.3 percent in the first age range and by 29.3 percent in the second, with large percentage falls also in average annual earnings (19.3 and 14.8 percent). However, average annual consumption declines by less as average net assets falls by 9.5 and 16.5 percent.

Single Females: The labor supply response for single females differs slightly from single and married males in that while non-employment rates rise and full-time employment rates fall, there is also a marked increase in part-time employment and a smaller decline in annual hours overall. All of the other patterns are quite similar.

\section{Eliminating the earnings tax}

Married couples: Eliminating the earnings tax reduces non-employment, particularly for husbands after reaching age 62 . However, there is also a slight increase in employment before age 62 for husbands, although average annual hours is essentially unchanged. After age 62, the full-time employment rate of husbands increases by 9.2 percentage points, while the part-time rate falls by 4.6 percentage points. The overall increase in average annual hours is by 145 hours (15.6 percent). And, there is also an increase for wives after age 62, by 56 hours (19.2 percent).

Household earnings and consumption both increase slightly in the first period, the latter in small part due to a reduction in net assets (presumably, to smooth consumption). The takeup rate rises essentially to 100 percent, as eligibility is unaffected by earnings, and there is a considerable increase in average benefits, both because earnings are not taxed and because everyone who is eligible receives benefits. Net assets rise considerably in the second period as some of the extra income is saved.

Single Males: The effect on the labor supply pattern of single males is dramatic. Although there is little drop in the non-employment rate after age 62, there is a large shift from parttime to full-time work that is essentially offsetting (by about 20 percentage points), increasing average annual hours by 271 (50.0 percent). Before age 62, there is a small increase in both part- and full-time work, increasing annual hours by 6.6 percent. As with married couples, net assets fall slightly in the first period and increase significantly in the second. 
Single Females: The effect on the labor supply pattern of single females is similar to that of single males, although somewhat less dramatic in that the increase in the full-time employment rate after age 62 is not completely offset by the decline in the part-time employment rate. Average annual hours thus increases by less than for single males, although still substantially (from 737 to 950, 28.9 percent). All other effects are also quite similar as the other groups.

\section{No benefits until age 65 (eliminating early retirement): 60}

Married couples: Eliminating early retirement increases employment rates of husbands by a small amount before and by a significant amount after age 62. As with the other experiments, there is a much smaller effect on the labor supply of wives. Household earnings and consumption are essentially unchanged in the first period and there is a slight increase in net assets in order to augment consumption in the second period when there are no social security benefits between 62 and 64 . The increase in household earnings in the second period and the fall in net assets compensate to leave household consumption essentially unchanged.

Single Males: The labor supply response of single males is similar to eliminating the earnings tax. Although the first is obviously welfare improving, they both provide a strong incentive to work after age 62 and the single males again shift from part- to full-time work. The effect on annual hours after age 62 is of the same order of magnitude. The labor response after age 62 is so large that consumption also increases relative to the baseline as does net assets.

Single Females: As with males, the response of single females is also similar to the response to eliminating the earnings tax, namely a strong substitution of full-time for parttime work after age 62 and the maintenance of consumption after age 62 at pre-treatment levels.

\section{No benefits until age $\mathbf{7 0}$}

Married couples: Eliminating all benefits until age 70 has essentially no additional impact on behaviors before age 62 above that of eliminating benefits until age 65 in the previous experiment. However, the effects after age 62 are different and not monotonic with respect to the previous experiment. Although non-employment rates continue to fall and full-time employment rates are higher for husbands and wives relative to the previous experiment, part-time employment rates of husbands fall. And, while consumption rose after age 62 in the previous experiment, eliminating benefits up to age 70 reduces consumption relative to the baseline even though net assets fall by an additional large amount (from 117,624 in the previous experiment to 102,787 ).

Single Males: For single males, there are further effects on behaviors before age 62 of eliminating benefits up to age 70 beyond those of the previous experiment. Annual hours and earnings fall even further. After age 62, again effects are not monotonic. Annual hours and earnings, though larger than in the baseline, are smaller than in the previous experiment. Consumption also falls after age 62 as does net assets, although they both rose relative to the

\footnotetext{
${ }^{60}$ Increasing the early or normal retirement age would possibly lead to an increase in filings for disability. The evidence in the literature is mixed. Bound et al (2004) conclude that increasing the normal retirement age to 67 (while correspondingly reducing benefits at all early retirement ages) would have essentially no effect on the DI application rate of single men. On the other hand, Duggan et al (2007) estimate that the 1983 reform in which the normal retirement age was increased to 67 caused significant increases in DI enrollment of 0.6 percentage points for men and 0.9 percentage points for women aged 45-64 in 2005. Although these changes represent large proportional increases in DI enrollment rates, they are nevertheless small when compared to the large policy-induced employment and hours responses predicted by our model.
} 
baseline in the previous experiment. The elimination of the social security benefits that would otherwise be received is too large for an optimal labor supply adjustment to compensate so as to maintain consumption and savings levels.

Single Females: The effect on single females mirrors the effect on single males.

\section{Budget and Welfare Implications}

Table 15 illustrates the trade-off, for three of the policy reforms, between the welfare losses that would be suffered by the individuals in the no-pension sample and the increase in net revenues to the social security fund. The policy is assumed to have been implemented in 1992 , with their impacts calculated over the following 15 years, through $2006 .{ }^{61} \mathrm{We}$ consider a reduction in benefits of 50 percent, an increase in the retirement age to 70 and an increase in the payroll tax to 15 percent. The first column in table 15 shows the (populationweighted) average percentage fall in the present discounted value of utility over the 19922006 period due to each policy change. These welfare losses are presented separately for single males, single females and for married couples (the level of the utility of couples at any period is the sum of the utilities of husbands and wives who are still alive). We present also the corresponding dollar changes in the present discounted value of consumption and in total hours worked over the same period. The fourth column presents the change in the average net social security revenue over the period, that is, the payments into social security through the payroll tax minus social security benefits (taking into account the earnings tax). Finally, we show in column five the change in the per-year net social security revenue for the population corresponding to our sample.

Consider first the impact of these policy changes on welfare. The fall in the present value of utility due to a 50 percent reduction in benefits is estimated to be 7.7 percent for single males, 4.4 percent for single women and 8.4 percent for married couples. The effects of increasing the retirement age to 70 are of similar magnitudes: a fall of 8.1 percent for single males, 5.2 percent for single females and 9.8 percent for married couples. The effect of these policy changes on welfare are considerably larger than the effect of the 15 percent increase in the payroll tax: the corresponding losses are $.1, .1$, and 1.9 percent. The compositional effects of these policy changes, in terms of changes in the optimal choice of consumption and hours worked, differ. In particular, all three policy changes induce a fall in consumption, and of reasonably similar magnitudes. However, although the benefit reduction and increased retirement age lead to an increase in hours worked, a larger increase for the first than for the second policy change, the increased payroll tax leads to a significant reduction in hours worked. This (optimal) reduction in hours worked accounts for the much smaller drop in welfare from this policy. What is taken to be the measure of welfare, utility or consumption, is thus important in considering the welfare impact of these alternative policies.

The last column in the table shows the effect of each policy on the social security budget balance. In all cases, these policies generate positive net revenues. However, there is a clear ordering. Reducing the social security benefit by 50 percent would have increased net revenues by $\$ 120$ million, the increase in the payroll tax to 15 percent by $\$ 245$ million and the increase in the retirement age by $\$ 318$ million. Given the estimated welfare losses associated with these changes, reducing the benefit by 50 percent would be the least efficacious policy change. However, there is a marked trade-off between the other two policies. The 30 percent larger increase in net revenues associated with the increased

\footnotetext{
${ }^{61}$ Over the 15 years, average survival in the baseline simulation is 12.9 for single males, 13.1 for single females and 14.6 for the longest living spouse of a married couple.
} 
retirement age relative to the increased payroll tax is gained at the expense of a considerably larger fall in welfare. Thus, a policymaker would have to weigh the trade-off in choosing among these two policy changes.

There are a number of important caveats to this analysis. With respect to the payroll tax increase, both the welfare losses and the revenue gains would be considerably larger for a population that consisted of younger individuals who faced longer working lives. Without solving the model back to earlier ages, which is beyond the scope of the present enterprise, it is not possible to tell how much welfare would fall nor how much net revenues would increase. In addition, all of the policy effects would be different, even calculated only over the ages of the sample, if the policy had been in effect at earlier ages. Policy effects would be different because households would have arrived at the sample ages in 1992 with different levels of their state variables (assets, work experience). Because of the special nature of the sample and these caveats, these results should be taken as illustrative of the kind of trade-offs of which policymakers need to be cognizant when modifying the current social security system.

\section{Conclusions}

In this paper, we have specified and estimated a dynamic model of retirement and savings decisions for a low income subsample of households from the Health and Retirement Study. The model incorporated a discrete employment decision (non-employment, part-or full-time employment) and a continuous consumption decision for both unmarried men and women and for married couples. Additional features of the model included a detailed specification of social security rules, limited borrowing, probabilistic job offers from new firms specifying the wage and health insurance availability, a bequest motive, uncertain health and survival, wages that evolve with labor market experience and job tenure, and unobserved heterogeneity in preferences, wages and health status. The model was estimated using the method of indirect inference. The estimated model was shown to reasonably fit many different aspect of the data.

The model was used to understand the impact of changes in social security rules on household labor supply, income and consumption. The estimated model forecasts large and heterogeneous behavioral responses, with those of singles generally exceeding those of married individuals, and those of husbands being considerable larger than those of wives. In case of a reduction in social security benefits of 25 percent, we find moderately large reductions in labor supply at ages below 62 (2-3 percent for married, 5-7 percent for singles), and large increases in annual hours worked at ages 62-69 (12 percent for married, 8 percent for singles). Increasing the social security payroll tax to 15 percent, a large change in itself, is predicted to lead to considerable reductions in annual hours worked at all ages, with average annual hours of working at ages 62-69 falling by 5 percent for wives, 14 percent for single women, 16 percent for husbands, and 29 percent for single males, with similar but somewhat smaller reductions at ages 51-61. These reductions take the form of increases in both non-employment and in part-time work, except for single males for whom the part-time rate drops.

We find qualitatively similar responses in labor supply to the removal of the earnings test, the elimination of early retirement, and a postponement of the earliest retirement age to 70 . In all cases, we predict sharp increases in average annual hours of work (with estimates varying between 16 and 52 percent) and in full-time employment at ages 62 to 69 . For couples most of this is due to a reduction in non-employment, while for singles it is primarily due to a shift from part-time into full-time employment. Again, we find smaller changes in the labor supply of wives compared to that of husbands, and somewhat smaller 
(although still substantial) increases for single women compared to single men. The policy changes have very little effect on the labor supply of married individuals at ages below 62, but this is not the case for singles for whom we predict varying positive and negative responses in labor supply that depend on the exact nature of the policy change. For example, removal of the work disincentives embedded in the earnings test leads to a 6.6 (2.6) percent increase in annual hours of work for single males (females) at ages 51-61, but has a negligible impact on the labor supply of married couples in that age group.

Overall, the counterfactual experiments indicate that the changes in the social security rules we consider would lead to large behavioral responses in the work behavior of low income households, which in turn would have a substantial financial impact on the social security system. At the same time, we found the employment responses to these policy changes to be accompanied by modest, but not inconsequential, changes in net assets holding, indicating that both labor supply and savings decisions play important roles in mitigating the consequences for consumption and welfare of benefit reductions and of the elimination or postponement of the early and normal retirement age.

The policy experiments also illustrate the existence of potentially important tradeoffs faced by policy makers in balancing consumer welfare losses against revenue increases. We find that if the government had reduced social security benefits by 50 percent in 1992, the welfare (present discounted utility flow) loss to the population represented by the nopension sample would have ranged from 4 percent for single females to 8 percent for married couples. The welfare loss would have been of a similar magnitude if the retirement age had been increased to 70 in 1992 . However, the net revenue gain associated with the benefit reduction would have been only about 40 percent as large as that from the increased retirement age. In contrast, the welfare loss from increasing the payroll tax to 15 percent would have resulted in less than a 2 percent fall in welfare and an increase in net revenues that was about 75 percent as large as that from the increased retirement age. Thus, while a policymaker would necessarily have preferred either of the latter two policies, the choice between them would depend on how the larger net revenue obtained from one policy is weighed against its greater welfare loss.

\section{Acknowledgments}

We are grateful for support from the National Institute on Aging grant AG14862. The views and opinions offered in this article do not necessarily reflect those of the Federal Reserve Bank of New York or the Federal Reserve System as a whole.

\section{References}

Barmby T, Smith N. Household Labour Supply in Britain and Denmark. Applied Economics. 2001; 33:1109-1116.

Benitez-Silva, H.; Heiland, F. Early Claiming of Social Security Benefits and Labor Supply Behavior of Older Americans. Mimeo: SUNY Stony Brook; 2006.

Berkovec J, Stern S. Job Exit Behavior of Older Men. Econometrica. 1991; 59:189-210.

Bernheim BD, Levin L. Social Security and Personal Savings: An Analysis of Expectations. American Economic Review. 1989; 79:97-102.

Blau DM. Labor Force Dynamics of Older Men. Econometrica. 1994; 62:117-156. [PubMed: 12290260]

Blau DM, Gilleskie DB. The Role of Retiree Health Insurance in the Employment Behavior of Older Men. NBER WP 10100, forthcoming in the International Economic Review. 2005

Blau DM, Gilleskie DB. Health Insurance and Retirement of Married Couples. Journal of Applied Econometrics. 2006; 21:935-953. 
Bound, J.; Stinebrickner, T.; Waidmann, T. Using a Structural Retirement Model to Simulate the Effect of Changes to the OASDI and Medicare Programs. University of Michigan, Michigan Retirement Research Center; 2004. wp091

Browning, M.; Chiappori, P.; Lewbel, A. Mimeo: Boston College; 2006. Estimating Consumption Economies of Scale, Adult Equivalence Scales, and Household Bargaining Power.

Coile C, Diamond P, Gruber J, Jousten A. Delays in Claiming Social Security Benefits. Journal of Public Economics. 2002:357-386.

Duggan M, Singleton P, Song J. Aching to Retire? The Rise in the Full Retirement Age and its Impact on the Disability Rolls. Journal of Public Economics. 2007; 91:1327-1350.

Dey M, Flinn C. An Equilibrium Model of health Insurance and Wage Determination. Econometrica. 2005; 73:571-628.

Diamond PA, Hausman JA. Individual Retirement and Savings Behavior. Journal of Public Economics. 1984; 23:81-114.

Dominitz J, Manski CF, Heinz J. Will Social Security Be There For You?: How Americans Perceive Their Benefits. NBER 9798. 2003

Duggan M, Singleton P, Song J. Aching to Retire? The Rise in the Full Retirement Age and its Impact on the Disability Rolls. NBER Working Paper No. 11811. 2005

Eckstein Z, Wolpin KI. Why Youths Drop Out of High School: The Impact of Preferences, Opportunities, and Abilities. Econometrica. 1999; 67:1295-1339.

Feldstein MS. Social Security, Induced Retirement, an Aggregate Capital Accumulation. Journal of Political Economy. 1974; 84:905-926.

Fields, G.; Mitchell, O. Retirement, Pensions, and Social Security. Cambridge: The MIT Press; 1984.

French E, Jones JB. The Effects of Health Insurance and Self-Insurance on Retirement Behavior. Federal Reserve Bank of Chicago, WP 2001-19. 2004

French E. The Effects of Health, Wealth, and Wages on Labour Supply and Retirement Behaviour. Review of Economic Studies. 2005; 72:395-427.

Gallant AR, Tauchen G. Which Moments to Match? Econometric Theory. 1996; 12:657-681.

Gilleskie D. A Dynamic Stochastic Model of Medical Care and Work Absence. Econometrica. 1998; 66:1-46.

Gourieroux, C.; Monfort, A. Simulation-Based Econometric Methods. Oxford: Oxford University Press; 1996.

Gourieroux C, Monfort A, Renault E. Indirect Inference. Journal of Applied Econometrics. 1993; 8:S85-S118.

Gustman AL, Steinmeier TL. A Structural Retirement Model. Econometrica. 1986; 54:555-584.

Gustman AL, Steinmeier TL. Employer-Provided Health Insurance and Retirement Behavior. Industrial and Labor Relations Review. 1994; 48:124-140.

Gustman AL, Steinmeier TL. Retirement in a Family Context: A Structural Model for Husbands and Wives. Journal of Labor Economics. 2000; 18:503-545.

Gustman AL, Steinmeier TL. The Social Security Early Entitlement Age in a Structural Model of Retirement and Wealth. Journal of Public Economics. 2005; 89:441-463.

Honig M. Retirement Expectations by Race, Ethnicity and Gender. The Gerontologist. 1996:36. [PubMed: 8932408]

Honig M. Married Women's Retirement Expectations: Do Pensions and Social Security Matter? American Economic Review Papers and Proceedings. 1998; 88:202-206.

Hubbard G, Skinner J, Zeldes S. Precautionary Saving and Social Insurance. Journal of Political Economy. 1995; 105:360-399.

Hurd M. Mortality Risks and Bequests. Econometrica. 1989; 57:779-814.

Hurd MD, McGarry K. Evaluation of the Subjective Probabilities of Survival in the Health and Retirement Study. Journal of Human Resources. 1995; 30:S268-S292.

Hurd MD, McGarry K. The Predictive Validity of Subjective Probabilities of Survival. The Economic Journal. 2002; 112:966-985. 
Juster FT, Suzman R. An Overview of the Health and Retirement Study. Journal of Human Resources. 1995:S7-S56.

Keane M, Wolpin KI. The Solution and Estimation of Discrete Choice Dynamic Programming Models by Simulation and Estimation: Monte Carlo Evidence. Review of Economics and Statistics. 1994; 76:648-672.

Keane M, Wolpin KI. The Career Decisions of Young Men. Journal of Political Economy. 1997; 105:473-522.

Keane M, Wolpin KI. Equalizing Race Differences in School Attainment and Labor Market Success. Journal of Labor Economics. 2000; 18:614-652.

Keane M, Wolpin KI. The Effect of Parental Transfers and Borrowing Constraints on Educational Attainment. International Economic Review. 2001; 42:1051-1103.

Lumsdaine, R.; Stock, JH.; Wise, DA. Three Models of Retirement: Computational Complexity vs. Predictive Validity. In: Wise, D., editor. Topics in the Economics of Aging. Chicago: University of Chicago Press; 1992.

Lumsdaine, R.; Stock, JH.; Wise, DA. Pension Plan Provisions and Retirement: Men and Women, Medicare and Models. In: Wise, DA., editor. Studies in the Economics of Aging. Chicago: University of Chicago Press; 1994.

Lumsdaine, R.; Stock, JH.; Wise, DA. Why are Retirement Rates So High at Age 65? In: Wise, DA., editor. Advances in the Economics of Aging. Chicago: Chicago University Press; 1996.

Moffitt, RA. Life-Cycle Labor Supply and Social Security: A Time Series Analysis. In: Burtless, G., editor. Work, Health and Income Among the Elderly. Washington, DC: The Brookings Institution; 1987.

Phelan, C.; Rust, J. U.S. Social Security Policy: A Dynamic Analysis of Incentives and Self-Selection. mimeo: University of Wisconsin; 1991.

Rust, J.; Buchinsky, M.; Benitez-Silva, H. Mimeo: University of Maryland; 2003. Dynamic Structural Models of Retirement and Disability.

Rust J, Phelan C. How Social Security and Medicare Affect Retirement Behavior in a World of Incomplete Markets. Econometrica. 1997; 65:781-831.

Sickles R, Taubman P. An Analysis of the Health and Retirement Status of the Elderly. Econometrica. 1986; 54:1339-1356.

Stock J, Wise DA. Pensions, the Option Value of Work, and Retirement. Econometrica. 1990; 58:1151-1180.

Tartari, Melissa. Indirect Inference with Panel Data. Mimeo: Yale University; 2006. 2006

Van der Klaauw W. Female Labor Supply and Marital Status Decisions: A Life Cycle Model. Review of Economics Studies. 1995; 63:199-235.

Van der Klaauw, W. Mimeo: UNC-Chapel Hill; 2000. On the Use of Expectations Data in Estimating Structural Dynamic Models: An analysis of career choices.

Wolpin KI. An Estimable Dynamic Stochastic Model of Fertility and Child Mortality. Journal of Political Economy. 1984; 92:852-875.

Wolpin, KI. Commentary on "Analysis of Choice Expectations in Incomplete Scenarios". In: Manski, CF., editor. Journal of Risk and Uncertainty. Vol. 19. 1999. p. 67-69. 
Table 1

Descriptive Statistics of Initial State Variables - Estimation Sample

\begin{tabular}{|c|c|c|c|c|}
\hline & \multicolumn{2}{|c|}{ Single } & \multicolumn{2}{|c|}{ Married } \\
\hline & Male & Female & Male & Female \\
\hline \multicolumn{5}{|l|}{ Mean Age: } \\
\hline Unweighted & $56.2(3.2)^{a}$ & $55.9(3.3)$ & $59.4(5.9)$ & $55.2(4.5)$ \\
\hline Weighted & 56.2 & 55.8 & 59.5 & 55.4 \\
\hline \multicolumn{5}{|l|}{$\%$ Black: } \\
\hline Unweighted & 37.8 & 43.3 & 18.9 & 18.5 \\
\hline Weighted & 23.4 & 28.7 & 11.5 & 11.4 \\
\hline \multicolumn{5}{|l|}{$\%$ Hispanic: } \\
\hline Unweighted & 13.5 & 15.7 & 19.3 & 18.1 \\
\hline Weighted & 12.4 & 12.4 & 13.3 & 12.3 \\
\hline \multicolumn{5}{|c|}{ Mean Highest Grade Completed: } \\
\hline Unweighted & $10.7(3.8)$ & $10.4(3.5)$ & $10.3(4.2)$ & $10.4(3.6)$ \\
\hline Weighted & 11.0 & 10.7 & 10.9 & 10.8 \\
\hline \multicolumn{5}{|c|}{ \% Ever had a DB Pension Job: } \\
\hline Unweighted & 34.0 & 17.3 & 50.0 & 23.5 \\
\hline Weighted & 37.1 & 17.4 & 54.3 & 24.7 \\
\hline \multicolumn{5}{|c|}{ Current Pension Income (household): } \\
\hline Unweighted & $1,615(4,642)$ & $480(2,603)$ & $4,055(7,010)$ & $4,055(7,010$ \\
\hline Weighted & 2,080 & 437 & 4,601 & 776 \\
\hline \multicolumn{5}{|c|}{ Mean Work Experience (total hours): } \\
\hline Unweighted & $57,501(28,545)$ & $41,308(29,119)$ & $72,963(21,583)$ & $31,685(27,932)$ \\
\hline Weighted & 57,422 & 41,768 & 72,971 & 31,302 \\
\hline \multicolumn{5}{|c|}{ Mean Current Job Tenure (hours): } \\
\hline Unweighted & $8,834(16,904)$ & $10,225(16,723)$ & $13,873(21,377)$ & $8,076(13,590)$ \\
\hline Weighted & 10,330 & 9,353 & 13,380 & 7,539 \\
\hline \multicolumn{5}{|c|}{ Mean Net Assets (no imputations): } \\
\hline Unweighted & $30,067(91,944)$ & $17,452(46,098)$ & \multicolumn{2}{|c|}{$114,900(398,056)$} \\
\hline Weighted & 34,639 & 24,084 & \multicolumn{2}{|c|}{126,874} \\
\hline \multicolumn{5}{|c|}{ Median Net Assets (no imputations): } \\
\hline Unweighted & 500 & 0 & \multicolumn{2}{|c|}{30,500} \\
\hline Weighted & 750 & 35 & \multicolumn{2}{|c|}{41,500} \\
\hline \multicolumn{5}{|c|}{ Mean Net Assets (imputations): } \\
\hline Unweighted & $46,070(111,371)$ & $30,133(65,116)$ & \multicolumn{2}{|c|}{$118,853(286,133)$} \\
\hline Weighted & 57,098 & 39,345 & \multicolumn{2}{|c|}{132,327} \\
\hline \multicolumn{5}{|c|}{ Median Net Assets (imputations): } \\
\hline Unweighted & 1,850 & 1,000 & \multicolumn{2}{|c|}{48,000} \\
\hline Weighted & 5,150 & 1,500 & \multicolumn{2}{|c|}{56,700} \\
\hline \multicolumn{5}{|c|}{ Mean Number of Covered Quarters: } \\
\hline Unweighted & $93.2(40.2)$ & $62.2(43.7)$ & $107.6(45.7)$ & $55.1(39.4)$ \\
\hline
\end{tabular}

J Econom. Author manuscript; available in PMC 2011 May 10. 


\begin{tabular}{|c|c|c|c|c|}
\hline & \multicolumn{2}{|c|}{ Single } & \multicolumn{2}{|c|}{ Married } \\
\hline & Male & Female & Male & Female \\
\hline Weighted & 95.1 & 63.2 & 110.6 & 55.8 \\
\hline \multicolumn{5}{|l|}{ Mean AIME: } \\
\hline Unweighted & $931(741)$ & $499(528)$ & $1,276(864)$ & $390(418)$ \\
\hline Weighted & 1,025 & 504 & 1,363 & 402 \\
\hline \multicolumn{5}{|l|}{$\%$ Poor Health: } \\
\hline Unweighted & 51.7 & 48.2 & 33.7 & 32.2 \\
\hline Weighted & 47.2 & 45.3 & 30.7 & 29.4 \\
\hline \multicolumn{5}{|c|}{ \% With Employer Health Insurance: } \\
\hline Unweighted & 16.9 & 21.4 & 18.2 & 11.4 \\
\hline Weighted & 20.9 & 23.6 & 18.4 & 11.6 \\
\hline \multicolumn{5}{|c|}{ \% With Employer Health Insurance when Retired: } \\
\hline Unweighted & 7.0 & 10.1 & 12.1 & 6.5 \\
\hline Weighted & 8.6 & 11.9 & 12.5 & 6.8 \\
\hline \multicolumn{5}{|l|}{$\%$ Never Married: } \\
\hline Unweighted & 27.4 & 19.8 & 0.0 & 0.0 \\
\hline Weighted & 29.5 & 17.4 & 0.0 & 0.0 \\
\hline \multicolumn{5}{|c|}{$\%$ Chance Work Full-Time at Age 62: } \\
\hline Unweighted & $55.1(41.0)$ & $53.9(39.6)$ & $57.1(39.6)$ & $42.8(38.6)$ \\
\hline Weighted & 54.3 & 54.2 & 57.4 & 40.5 \\
\hline \multicolumn{5}{|l|}{$\%$ Chance Live to Age $75:$} \\
\hline Unweighted & $51.5(35.2)$ & $58.8(35.0)$ & $60.7(33.1)$ & $61.1(30.3)$ \\
\hline Weighted & 50.4 & 58.3 & 60.6 & 61.3 \\
\hline \multicolumn{5}{|l|}{$\%$ Chance Live to Age $85:$} \\
\hline Unweighted & $31.9(34.2)$ & $44.2(37.3)$ & $40.4(33.7)$ & $43.0(32.6)$ \\
\hline Weighted & 31.3 & 43.2 & 39.8 & 42.0 \\
\hline \multicolumn{5}{|c|}{$\%$ Chance Leave a Bequest of $\$ 10,000$ : } \\
\hline Unweighted & $36.3(44.0)$ & $31.5(42.2)$ & $55.0(43.7)$ & $49.0(43.4)$ \\
\hline Weighted & 38.9 & 35.2 & 56.6 & 52.7 \\
\hline \multicolumn{5}{|c|}{$\%$ Chance Leave a Bequest of $\$ 100,000$ : } \\
\hline Unweighted & $11.6(27.6)$ & $10.8(10.8)$ & $25.8(38.0)$ & $21.1(35.7)$ \\
\hline Weighted & 14.2 & 13.5 & 28.5 & 24.0 \\
\hline \multicolumn{5}{|c|}{ Expected Social Security Benefits: } \\
\hline Unweighted & $580(237)$ & $573(294)$ & $691(294)$ & $453(228)$ \\
\hline Weighted & 573 & 576 & 704 & 463 \\
\hline Number of Observations & 230 & 363 & 525 & 525 \\
\hline
\end{tabular}

${ }^{a}$ Standard deviation in parentheses. 











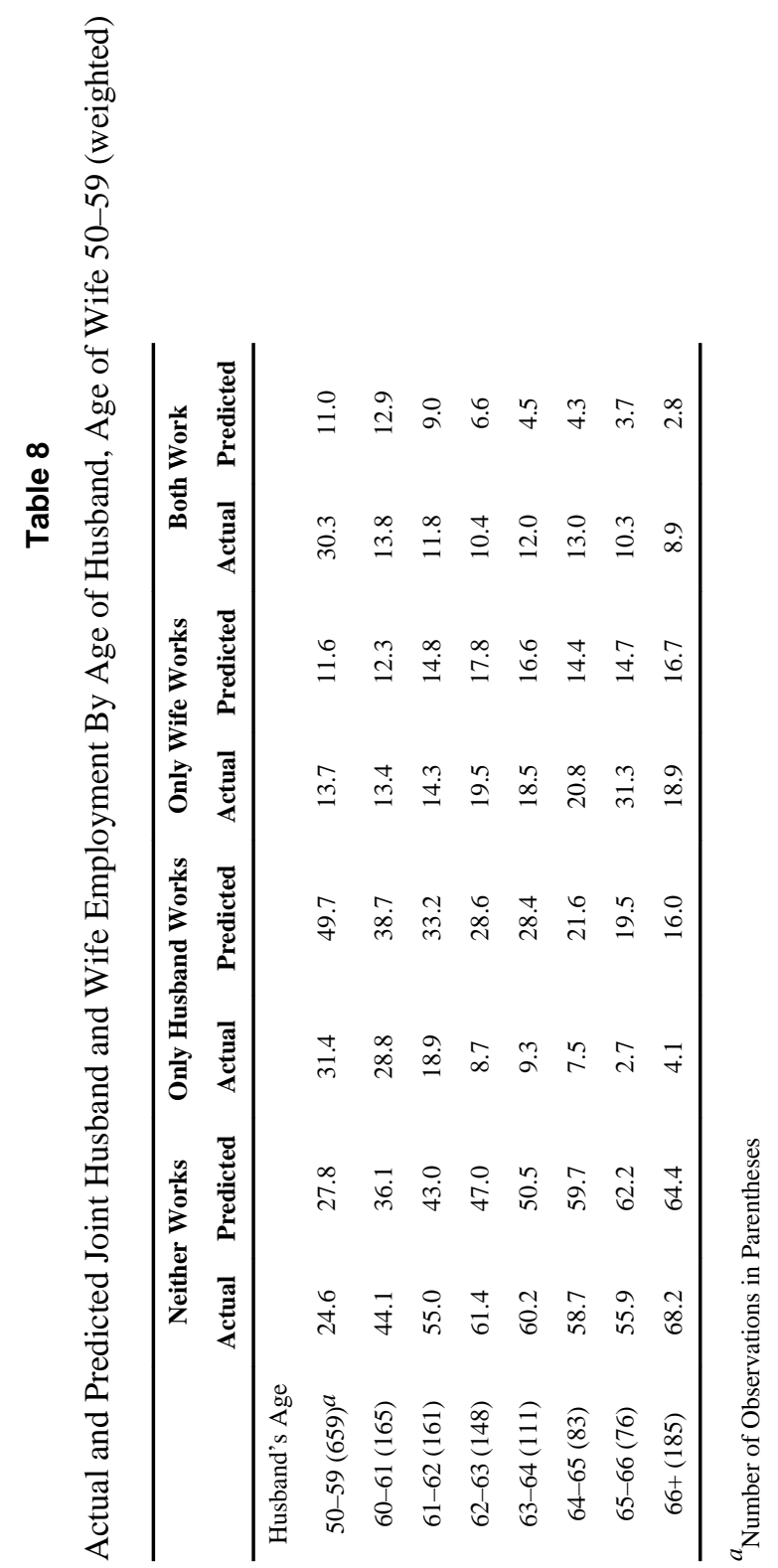






J Econom. Author manuscript; available in PMC 2011 May 10. 
Table 10

Selected Characteristics by Type- Singles

\begin{tabular}{lrrrr}
\hline & \multicolumn{2}{c}{ Females } & \multicolumn{2}{c}{ Males } \\
& Type 1 & Type 2 & Type 1 & Type 2 \\
\hline Proportion & .582 & .418 & .987 & .013 \\
Highest Grade Completed & 10.7 & 10.8 & 11.0 & 10.9 \\
Not Working & .791 & .154 & .607 & .686 \\
Work Full Time & .151 & .567 & .284 & .291 \\
Annual Earnings & 3,837 & 11,455 & 5,729 & 8,258 \\
Net Worth & 20,383 & 26,038 & 38,346 & 38,062 \\
Consumption & 6,872 & 9,351 & 9,110 & 9,442 \\
\hline
\end{tabular}

J Econom. Author manuscript; available in PMC 2011 May 10. 
Table 11

Selected Characteristics by Type - Married Couples (Both Age 51-61)

\begin{tabular}{|c|c|c|c|c|}
\hline & $\begin{array}{l}\text { Type } 1 \text { Husb. } \\
\text { Type } 1 \text { Wife }\end{array}$ & $\begin{array}{l}\text { Type } 1 \text { Husb. } \\
\text { Type } 2 \text { Wife }\end{array}$ & $\begin{array}{l}\text { Type } 2 \text { Husb. } \\
\text { Type } 1 \text { Wife }\end{array}$ & $\begin{array}{l}\text { Type } 2 \text { Husb. } \\
\text { Type } 2 \text { Wife }\end{array}$ \\
\hline Proportion & .060 & .012 & .746 & .182 \\
\hline \multicolumn{5}{|c|}{ Highest Grade Completed } \\
\hline Husband & 11.7 & 11.2 & 11.2 & 10.9 \\
\hline Wife & 11.5 & 11.1 & 11.0 & 10.7 \\
\hline \multicolumn{5}{|l|}{ Not Working } \\
\hline Husband & .327 & .462 & .297 & .601 \\
\hline Wife & .854 & .214 & .935 & .275 \\
\hline Both & .288 & .108 & .277 & .165 \\
\hline \multicolumn{5}{|c|}{ Work Full Time } \\
\hline Husband & .515 & .283 & .653 & .370 \\
\hline Wife & .120 & .706 & .051 & .647 \\
\hline Both & .055 & .200 & .028 & .237 \\
\hline \multicolumn{5}{|c|}{ Annual Earnings } \\
\hline Husband & 9,260 & 6,876 & 16,100 & 10,512 \\
\hline Wife & 2,331 & 10,458 & 1,047 & 9,262 \\
\hline Total & 11,591 & 17,334 & 17,147 & 19,774 \\
\hline Net Worth & 110,534 & 89,029 & 92,000 & 77,075 \\
\hline \multicolumn{5}{|c|}{ Consumption } \\
\hline Husband & 8,586 & 13,823 & 7,817 & 12,571 \\
\hline Wife & 8,642 & 2,819 & 9,246 & 3,049 \\
\hline Total & 17,228 & 16,642 & 17,062 & 15,623 \\
\hline
\end{tabular}




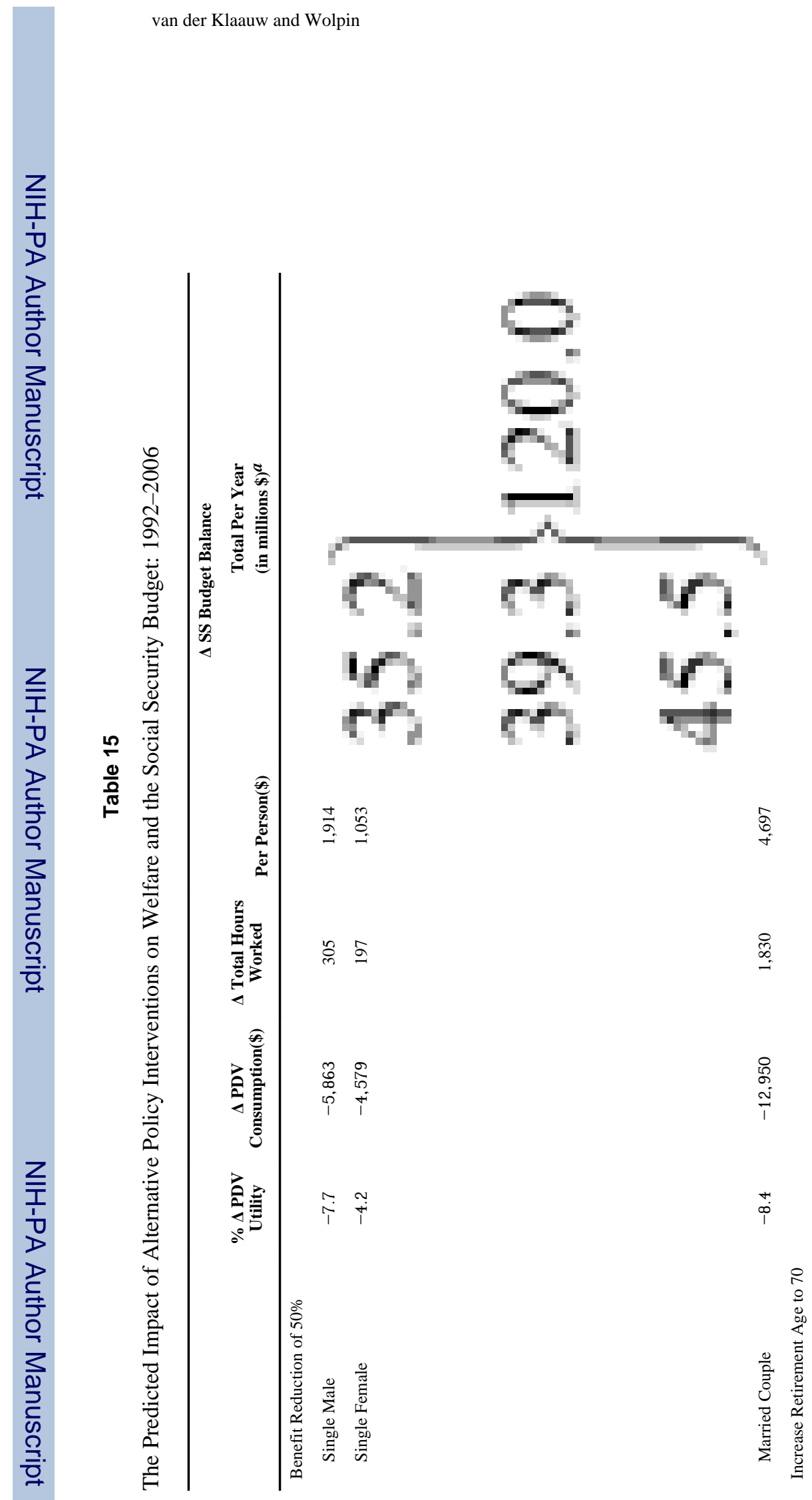

J Econom. Author manuscript; available in PMC 2011 May 10. 




$J$ Econom. Author manuscript; available in PMC 2011 May 10. 


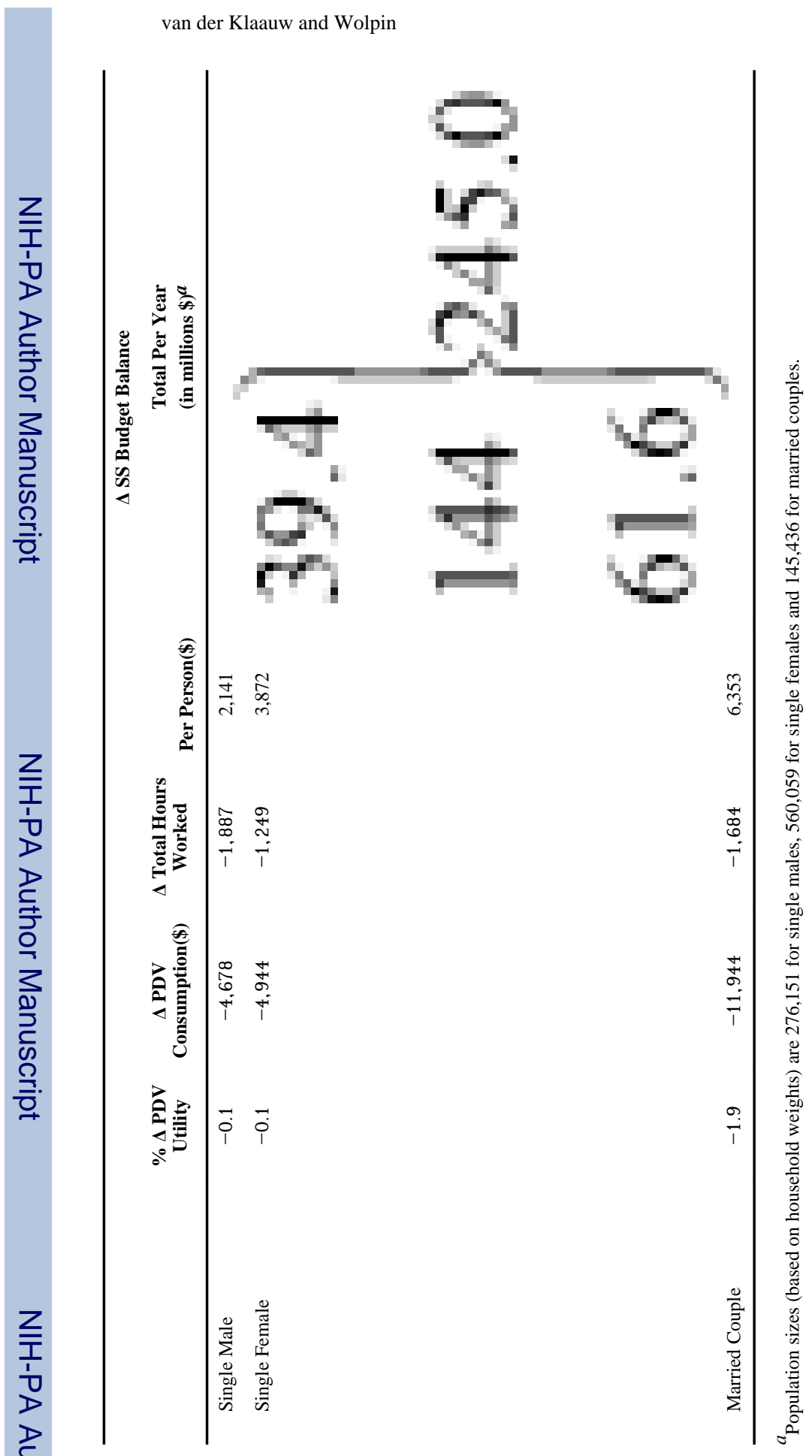

$J$ Econom. Author manuscript; available in PMC 2011 May 10. 


\section{Table A.1}

Utility function:

where $\mathrm{h}_{\mathrm{a}}^{*}=\mathrm{I}\left(\mathrm{h}_{\mathrm{a}}=1\right)+\sum_{\mathrm{j}=1}^{2} \sum_{\mathrm{k}} \gamma_{\mathrm{jk}} \mathrm{I}($ type $=\mathrm{j}$, sex $=\mathrm{k}) \mathrm{I}\left(\mathrm{h}_{\mathrm{a}}=2\right)$,

$\mathrm{h}_{\mathrm{a}} \mathrm{k}^{*}=\mathrm{h}_{\mathrm{a}}{ }^{*} \mathrm{I}(\operatorname{sex}=\mathrm{k})$,

$\mathrm{h}_{\mathrm{a}}{ }^{\mathrm{n}}=$ hours if new job; $\mathrm{h}_{\mathrm{a}}{ }^{\mathrm{o}}=$ hours if old job;

$\mathrm{D}_{\mathrm{r}}=1$ if race is black, $=0$ otherwise,

$\mathrm{D}_{\mathrm{m}}=1$ if married, $=0$ if single.

Pareto Weights:

$$
\begin{aligned}
& \theta_{\mathrm{m}}=\left[\left(1+\exp _{1}\left(_{1} \mathrm{I}\left(\text { type }_{\mathrm{m}}=1, \text { type }_{\mathrm{f}}=1\right)+\theta_{2} \mathrm{I}\left(\text { type }_{\mathrm{m}}=2, \text { type }_{\mathrm{f}}=1\right)+\theta_{3} \mathrm{I}\left(\text { type }_{\mathrm{m}}=1, \text { type }_{\mathrm{f}}=2\right)+\theta_{4} \mathrm{I}\left(\text { type }_{\mathrm{m}}=2, \text { type }_{1}\right)\right.\right.\right. \\
& \theta_{\mathrm{f}}=1-\theta_{\mathrm{m}},
\end{aligned}
$$

where type $\mathrm{m}_{\mathrm{m}}=$ husband type, type $_{\mathrm{f}}=$ wife type,

$\mathrm{a}_{\mathrm{m}}=\mathrm{age}$ of husband, $\mathrm{a}_{\mathrm{f}}=$ age of wife

Bequest Function:

$$
\mathrm{B}_{\mathrm{a}}\left(\mathrm{W}_{\mathrm{a}+1}\right)=\psi_{1} \mathrm{~W}_{\mathrm{a}+1}
$$

Wage Function:

$$
\log w_{a}=\sum_{j=1}^{2}\left(\omega_{j} I(\text { type }=j)+\omega_{j, f} I(\text { type }=j, \text { sex }=f)\right)+\omega_{3} I\left(h_{a}=1\right)+\omega_{4} H_{a}-0.5 \omega_{5} H_{a}^{2}+\omega_{6} T_{a}-0.5 \omega_{7} T_{a}^{2}+
$$

Survival Hazard Function:

$$
\pi_{a}^{S}=\left[1+\exp \left(\pi_{0}^{\mathrm{S}}+\pi_{1}^{\mathrm{S}} \mathrm{I}(\text { type }=2)+\pi_{2}^{\mathrm{S}} \mathrm{a}+\pi_{3}^{\mathrm{S}} \mathrm{Z}_{\mathrm{a}-1}+\pi_{4}^{\mathrm{S}} \mathrm{I}\left(\mathrm{hi}_{\mathrm{a}}>0\right)+\pi_{5}^{\mathrm{S}}\left(1-\mathrm{Z}_{\mathrm{a}-1}\right)\left(1-\mathrm{I}\left(\mathrm{hi}_{\mathrm{a}}>0\right)\right)+\pi_{6}^{\mathrm{S}} \mathrm{I}(\mathrm{sex}=\mathrm{f})+\pi\right.\right.
$$

Health Transition Function:

$$
\pi_{a}^{\mathrm{h}}=\left[1+\exp \left(\pi_{0}^{\mathrm{h}}+\pi_{1}^{\mathrm{h}} \mathrm{I}(\text { type }=2)+\pi_{2}^{\mathrm{h}} \mathrm{a}+\pi_{3}^{\mathrm{S}} \mathrm{Z}_{\mathrm{a}-1}+\pi_{4}^{\mathrm{h}} \mathrm{I}\left(\mathrm{hi}_{\mathrm{a}}>0\right)+\pi_{5}^{\mathrm{h}}\left(1-\mathrm{Z}_{\mathrm{a}-1}\right)\left(1-\mathrm{I}\left(\mathrm{hi}_{\mathrm{a}}>0\right)\right)+\pi_{6}^{\mathrm{h}} \mathrm{I(sex}=\mathrm{f}\right)+1\right.
$$

Health Insurance Offer Function: 


$$
\begin{aligned}
& \operatorname{Pr}\left(\mathrm{hi}_{\mathrm{a}}=1\right)=\pi_{\mathrm{a}}^{\mathrm{hi}}=\left[1+\exp \left(\pi_{0}^{\mathrm{hi}}+\pi_{1}^{\mathrm{hi}} \mathrm{Z}_{\mathrm{a}}+\pi_{2}^{\mathrm{hi}} \phi\right)\right]^{-1} \\
& \operatorname{Pr}\left(\mathrm{h}_{\mathrm{a}}=2 \text { isn ' t required I hi of fered }\right)=\left[1+\exp \left(\pi_{3}^{\mathrm{hi}}\right)\right]^{-1}
\end{aligned}
$$

Type Probability Function:

$$
\operatorname{Pr}(\text { type }=2)=\pi_{0}^{p}+\pi_{1}^{p_{W_{0}}}+\pi_{2}^{p_{H_{0}}}+\pi_{3}^{p_{I}} I(s e x=f)+\pi_{4}^{p_{a}}+\pi_{5}^{p_{1}} D_{r}+\pi_{6}^{p_{E}}+\pi_{7}^{p_{D}} D_{m} I(s e x=f)+\pi_{8}^{p}
$$

Net Asset Constraint:

$$
\begin{aligned}
& W_{a} \geq \underline{W}_{s}\left[1-\exp \left(-\xi_{s}\left(91-a_{j}\right)\right)\right] j=m, f ; \text { singles } \\
& W_{a} \geq \underline{W}_{c}\left[1-\exp \left(-\xi_{m}\left(91-a_{m}\right)-\xi_{f}\left(91-a_{f}\right)\right)\right] ; \text { couples }
\end{aligned}
$$



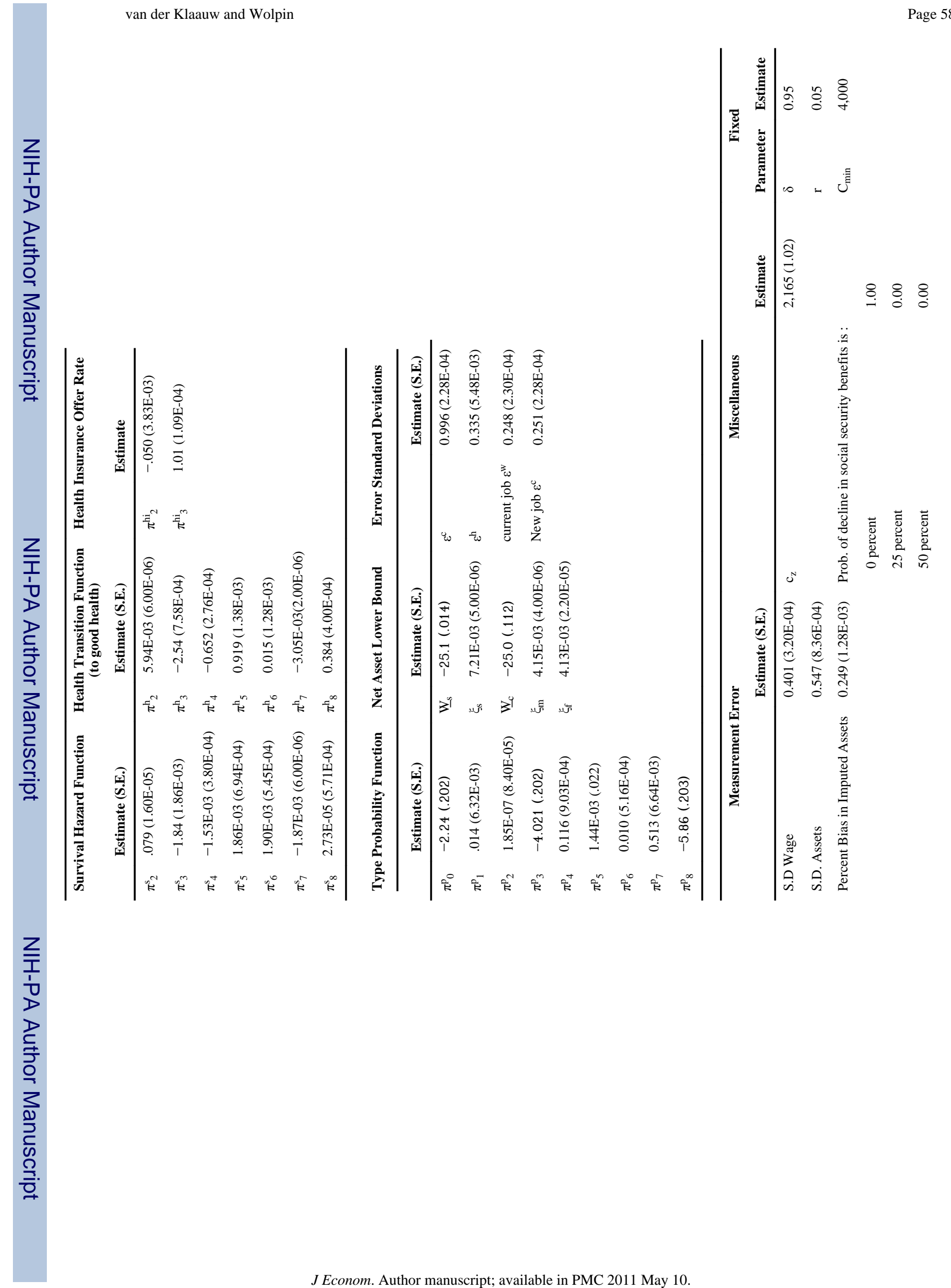

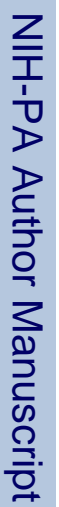




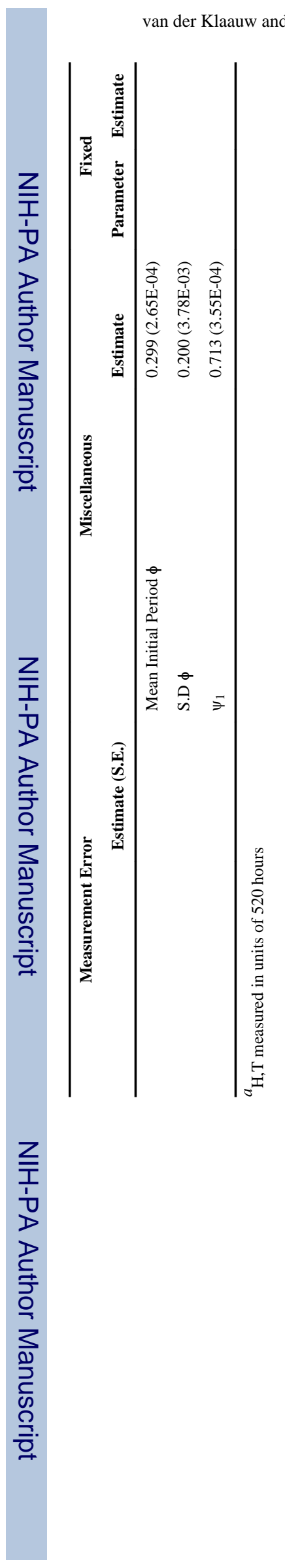

Page 59 